\title{
Incentives for energy efficiency in the EU Emissions Trading Scheme
}

\author{
Joachim Schleich $\cdot$ Karoline Rogge $\cdot$ Regina Betz
}

Received: 24 October 2007 / Accepted: 14 August 2008

(C) Springer Science + Business Media B.V. 2008

\begin{abstract}
This paper explores the incentives for energy efficiency induced by the European Union Emissions Trading Scheme (EU ETS) for installations in the energy and industry sectors. Our analysis of the National Allocation Plans for 27 EU Member States for phase 2 of the EU ETS (2008-2012) suggests that the price and cost effects for improvements in carbon and energy efficiency in the energy and industry sectors will be stronger than in phase 1 (2005-2007), but only because the European Commission has substantially reduced the number of allowances to be allocated by the Member States. To the extent that companies from these sectors (notably power pro-
\end{abstract}

J. Schleich $\cdot$ K. Rogge

Fraunhofer Institute for Systems and Innovation Research, Karlsruhe, Germany

J. Schleich $(\bowtie)$

Breslauer Strasse 48,

76139 Karlsruhe, Germany

e-mail: joachim.schleich@isi.fraunhofer.de

J. Schleich

Virginia Polytechnic Institute and State University,

Blacksburg, VA, USA

K. Rogge

Group for Sustainability and Technology, ETH,

Zurich, Switzerland

R. Betz

Center for Energy and Environmental Markets,

School of Economics, University of New South Wales,

Sydney, Australia ducers) pass through the extra costs for carbon, higher prices for allowances translate into stronger incentives for the demand-side energy efficiency. With the cuts in allocation to energy and industry sectors, these will be forced to greater reductions; thus, the non-ET sectors like household, tertiary, and transport will have to reduce less, which is more in line with the costefficient share of emission reductions. The findings also imply that domestic efficiency improvements in the energy and industry sectors may remain limited since companies can make substantial use of credits from the Kyoto Mechanisms. The analysis of the rules for existing installations, new projects, and closures suggests that incentives for energy efficiency are higher in phase 2 than in phase 1 because of the increased application of benchmarking to new and existing installations and because a lower share of allowances will be allocated for free. Nevertheless, there is still ample scope to further improve the EU ETS so that the full potential for energy efficiency can be realized.

Keywords Climate policy · Emission trading . Energy efficiency Innovation

\begin{tabular}{|c|c|}
\hline \multicolumn{2}{|c|}{ Abbreviations } \\
\hline BAT & best available technology \\
\hline BM & benchmark \\
\hline CCGT & combined gas cycle turbines \\
\hline $\mathrm{CDM}$ & clean development mechanism \\
\hline CHP & combined heat and power \\
\hline CITL & community independent transaction log \\
\hline
\end{tabular}




$\begin{array}{ll}\mathrm{CO}_{2} \mathrm{e} & \mathrm{CO}_{2} \text { equivalents } \\ \text { EC } & \text { European Commission } \\ \text { ET } & \text { emissions trading } \\ \text { EU } & \text { European Union } \\ \text { EUA } & \text { European Union allowance } \\ \text { EU ETS } & \text { EU Emissions Trading Scheme } \\ \text { JI } & \text { joint implementation } \\ \text { KM } & \text { Kyoto Mechanisms (i.e. JI, CDM) } \\ \text { NAP } & \text { National Allocation Plan } \\ \text { VET } & \text { verified emissions table }\end{array}$

\section{Introduction}

The European Union Emissions Trading Scheme (EU ETS) is the world's largest emissions trading system and the first international trading system for $\mathrm{CO}_{2}$ (Ellermann and Buchner 2007). It was launched in January 2005 and covers around 12,000 large greenhouse gas emitting installations in the energy and industry sectors: combustion installations with a rated thermal input capacity of at least $20 \mathrm{MW}$, refineries, coke ovens, steel plants, and installations producing cement clinker, lime, bricks, glass, pulp, and paper. In total, the EU ETS covers about $50 \%$ of Europe's $\mathrm{CO}_{2}$ emissions and $40 \%$ of its total greenhouse gas emissions. The EU ETS is made up of consecutive trading periods. The first trading period - often considered to be a "learning phase"-lasted from 2005 to 2007 (phase 1); the second trading period coincides with the Kyoto commitment period from 2008 to 2012 (phase 2). According to a recent proposal by the European Commission, the third trading period (phase 3) will last from 2013 to 2020 (CEC 2008a). As the European Union's key climate policy instrument, the EU ETS is expected to help the EU and the EU Member States reach their short- and long-term greenhouse gas emissions targets in a cost-efficient way (CEC 2000).

Emissions trading and incentives for energy efficiency and innovation

The EU ETS reflects a shift in environmental policy from command-and-control type environmental regulation, such as setting technology standards, towards market-based instruments. The EU ETS is a cap-andtrade scheme, where a central authority sets a limit (cap) on the amount of a pollutant that can be emitted by companies' installations covered by the scheme. Companies are issued emission allowances and, by the end of a particular period, must surrender the number of allowances equivalent to the amount of emissions caused by their installations during that period. Otherwise, sanctions have to be paid. Companies may emit more emissions than their initial allocation if they purchase extra allowances from other companies. Likewise, companies with low-cost abatement measures may choose to reduce emissions in order to sell their surplus allowances. Thus, companies with high-cost measures may purchase allowances while companies with lowcost measures may buy or sell allowances on a market where demand and supply schedules can be matched and an equilibrium market price emerges which reflects the scarcity of allowances in the system. Since all participants face the same marginal abatement costs, overall reduction costs are minimized (static efficiency). The price for allowances also sets monetary incentives to adopt new, more energy- and carbon-efficient technologies and services and to develop fundamentally new or significantly improved solutions (dynamic efficiency). In the EU ETS, these incentives not only apply to the firms directly covered by the EU ETS; there are also indirect effects in other parts of the value chain. For example, since the additional costs of covering greenhouse gas emissions are at least partially passed on and included in the product (e.g., electricity) prices, the EU ETS also increases incentives for improved energy efficiency on the demand side, such as in energy-intensive industries (e.g., aluminum producers) or private households. ${ }^{1}$ In terms of innovation policy, an emission trading system represents a demand-oriented technology regulation which leaves the technology selection process to the market rather than the regulator, i.e., companies are free to choose the most cost-efficient technology. Because emission trading systems allow for static and dynamic efficiency, they are often considered to be superior to other types of regulation. ${ }^{2}$

\footnotetext{
${ }^{1}$ Higher carbon efficiency is typically the result of improvements in energy efficiency. However, this is not necessarily the case for fuel switching, and it does not apply to carbon capture and storage either (IPCC 2005). We do not always make this distinction in the paper and the terms "carbon efficiency" and "energy efficiency" are used interchangeably.

${ }^{2}$ See Fischer (2005) for a recent overview of this topic.
} 
The role of national allocation plans in the EU ETS for energy efficiency

The extent of the technological change induced by the EU ETS crucially depends on the scheme's design (Gagelmann and Frondel 2005; Schleich and Betz 2005). Some key design elements of the scheme are governed by the EU Emission Trading Directive (CEC 2003a) and others are determined by country-specific National Allocation Plans (NAPs) of the individual Member States. At the macrolevel, NAPs define the cap, i.e., the total quantity of allowances available in each period (ET budget); at the microlevel, they determine how these allowances are allocated to individual installations. The size of the ET budget indicates whether the EU ETS is environmentally effective in terms of reducing $\mathrm{CO}_{2}$ emissions. More stringent ET budgets will lead to higher prices for European Union Allowances (EUAs) and thus greater incentives to improve energy and carbon efficiency, ceteris paribus. In the first phase, these incentives were low since the ET budgets turned out to be rather lenient, resulting in low prices for EUAs. ${ }^{3}$

At the macrolevel, the NAPs also determine to what extent the individual Member States rely on the EU ETS to achieve their emission targets. In particular, the NAPs establish how to "split the pie" between the EU ETS trading sectors on the one hand (i.e., energy and industry sectors) and the household, services, and transport sectors (i.e., nontrading sectors) on the other hand. The combined emission budgets for trading and nontrading sectors also determine to what extent Member States rely on domestic efforts and to what extent on the Mechanisms of the Kyoto Protocol to meet their emissions targets, i.e., International Emission Trading, the Clean Development Mechanism (CDM), and Joint Implementation (JI). In general, the use of credits from Kyoto Mechanisms can have direct and indirect impacts on energy efficiency. First, a greater use of these credits would translate into higher emission budgets for the EU ETS trading sectors and/or the nontrading sectors. This direct effect implies that, in the short run, fewer domestic measures would then be necessary to reach the national emission target. Second, the "Linking Direc-

\footnotetext{
${ }^{3}$ In addition, EUAs from phase 1 generally could not be transferred into phase 2 (see also Schleich et al. 2006). However, such banking of EUAs will be allowed starting from phase 2 onwards.
}

tive" (CEC 2004a) allows companies to use credits from Kyoto Mechanisms to cover their emissions under the EU ETS. Since the prices for credits from CDM and JI projects tend to be lower than those for EUAs (World Bank 2008), the use of credits from CDM and JI projects dampens the price for EUAs and thus lowers price and cost incentives for energy efficiency within the EU. The diffusion of energy- and carbon-efficient technologies may then be shifted from the EU to developing countries and emerging economies.

The allocation rules specified at the microlevel for existing and new installations and for closures shape the incentives for innovation and for long-term investments in low-carbon energy technologies and energy efficiency in the industry sectors. All NAPs need to be approved by the European Commission based on the criteria specified in the Emission Trading Directive (CEC 2003a) and in the NAP guidance (CEC 2004b, 2005).

Objective, methodology, and organization of the paper

In this paper, we analyze the notified and approved NAPs of the EU 27 Member States for phase 2 in terms of their incentives for innovation and energy efficiency. In particular, we evaluate the cost and price incentives for energy efficiency implied by the stringency of the cap. At the macrolevel, this analysis is based on three stringency criteria: the difference between the notified (and approved) ET budgets for phase 2 to (1) verified historical emissions in 2005, (2) the size of the ET budgets in phase 1, and (3) projected emissions in 2010. We also assess whether the burden sharing between trading and nontrading sectors is cost-efficient. This assessment is based on the criterion of a proportional split of the required emission reductions. Comparing the sizes of the submitted and notified ET budgets allows us to elicit the impact of the European Commission's assessments on the cost and price incentives for energy efficiency and on the cost-efficiency of the EU ETS in phase 2. Further, we explore to which extent the companies' use of Kyoto Mechanisms may crowd out domestic efficiency improvements in the energy and industry sector in the European Union. We calculate the maximum number of credits from Joint Implementation and the Clean Development Mechanism that companies are allowed to use and relate these to the stringency criteria derived above. To explore the microlevel incentives for energy efficiency, we assess the allocation 
rules for existing and new installations and for closures as specified in the NAPs based on insights from economic theory. Relating the rules for phase 2 to those for phase 1 at a general level, we can then identify areas where the incentives for energy efficiency have changed. Finally, we correlate the findings with the design features for a future EU ETS as laid out in the European Commission's proposal for a Directive for phase 3 as part of the "Climate action and renewable energy package" published in January 2008 (CEC 2008a, b, c).

To summarize, the paper contributes to the existing literature by evaluating the current rules of phase 2 of the EU ETS across Member States in terms of their impact on energy and carbon efficiency. Compared to prior work by Betz et al. (2006a), we extend and update the analysis at the macrolevel and introduce a new focus on primary and end-use energy efficiency at the macrolevel and microlevel as well as the new proposal for the third phase (CEC 2008a).

The paper is organized as follows: "Incentives for energy efficiency at the macrolevel" consists of the macrolevel analyses of the stringency and cost-efficiency of the ET budgets. In "Incentives for energy efficiency at the microlevel," we assess the allocation rules at the microlevel. A summary table in the "Appendix" provides a comprehensive overview of the relevant features of the macro and micro plans for the Member States included in this survey. Finally, "Conclusions" summarizes the main results and offers guidance for the future design of the EU ETS (and possibly other emissions trading schemes), aiming at improved incentives for energy efficiency. The concluding section also relates the main findings to the recent proposal by the European Commission for a Directive governing phase 3 of the EU ETS.

\section{Incentives for energy efficiency at the macro level}

The stringency of the combined national ET budgets of all the Member States determines the relationship between the supply and demand for EUAs and therefore influences the price and cost incentives for energy efficiency improvements. In phase 1 and phase 2, the ET budgets are typically made up of budgets for installations from individual industry and energy sectors. Initially, these sector budgets are determined by the respective Member States, usually based on a combination of historical emission levels or average bench- marks, growth projections, emission saving potentials and a compliance factor required to reach the overall ET budget. Then, the sector budgets are allocated to individual installations at the microlevel, typically based on their emissions share in a base period (rather than on output or capacity shares). Technically, most EU-15 Member States apply sector-specific compliance factors to guarantee that bottom-up allocation to individual installations does not exceed the sector budgets. In the simplest case, Member States set up only two budgets: one for all energy and one for all industry installations. Since most of the new Member States will easily reach their Kyoto targets, they neither use sector budgets nor compliance factors at the installation level.

For phase 1, verified emissions data (CEC 2006c) revealed that very few countries allocated EUAs in 2005 below the actual 2005 emission levels of the ET sector (Austria, Greece, Italy, Ireland, Spain, and the UK). As a consequence of this surplus allowance, in May 2006, prices for EUAs plummeted from around $€ 26 / \mathrm{EUA}$ to around $€ 10 / \mathrm{EUA}$ and to well below $€ 1 /$ EUA towards the end of the first trading period. According to Kettner et al. (2007), the surplus for 2005 amounts to about 100 million EUA. Since the emission level in the absence of the EU ETS cannot be determined (it is counterfactual), the real extent of possible overallocation cannot be determined. Ellerman and Buchner (2008) tentatively suggest that a substantial part of the surplus may have resulted from abatement activities. According to a survey conducted among participants by Point Carbon (Røine and Hasselknippe 2007), 65\% of respondents initiated internal abatement projects in 2006. This figure is significantly higher than in Point Carbon's survey for 2005. Also, the importance of innovation as a strategic response to the EU ETS was highlighted by a survey among the scheme's participants conducted on behalf of the European Commission (McKinsey and Ecofys 2006; AEA Technology Environment and Ecofys 2006). Nevertheless, the surplus of EUAs and the correspondingly low price provided little additional incentive to improve energy and carbon efficiency in phase 1 . Together with high uncertainty about governments' commitment to long-term targets, this meant that firms were not strongly motivated to develop energy-efficient and low-carbon technologies and services in phase 1 (Montgomery 2005).

For phase 2, therefore, the Commission developed its own criterion, based on 2005 verified emissions 
Table 1 Notified and accepted use of Kyoto Mechanisms by governments and companies

Governmental use of KM Permitted company use of KM in million ERU and CER/a

Sum of max. KM use

\begin{tabular}{llll}
\hline EU-27 notified & 109.4 & 373.8 & 483.3 \\
Accepted & 109.4 & 273.9 & 383.3 \\
\hline
\end{tabular}

Source: Fraunhofer ISI based on NAPs of Member States and NAP decisions of European Commission

data, economic growth, and carbon intensity trends (CEC 2006a, p. 3ff). Applying this criterion has led the European Commission to require budget cuts in all but four of the assessed plans (Denmark, France ${ }^{4}$, the UK, and Slovenia). The total ET budget originally proposed by the 27 Member States in their notified NAPs amounted to about 2,325 million tons of $\mathrm{CO}_{2} \mathrm{e}$ per annum (p.a.; one EUA corresponds to 1 ton of $\mathrm{CO}_{2} \mathrm{e}$ ). The European Commission reduced the total cap by $10.4 \%$ to 2,083 million EUAs p.a. ${ }^{5}$ In absolute terms, the budget adjustments were highest for Poland ( $\sim 6$ million EUAs p.a.) and Germany ( 29 million EUAs p.a.). In percentage terms, the budgets of Latvia $(\sim 56 \%)$, Estonia $(\sim 48 \%)$, and Lithuania $(\sim 47 \%)$ were reduced the most. The summary table in the "Appendix" shows these cuts in the ETS budgets for phase 2 in absolute and relative terms for each Member State. The required budget cuts were much higher for the new EU-12 Member States (175 million EUA/a or $-25.4 \%)$ than for the EU-15 Member States (68 million EUA/a or $-4.1 \%){ }^{6}$

The European Commission not only adjusted the ET budgets but also set a maximum amount of credits from Kyoto Mechanisms that companies may use to cover their emissions (see Tables 1 and 2). Taking into consideration the decisions of the European Commission, the maximum use of the Kyoto Mechanisms for companies

\footnotetext{
${ }^{4}$ France's NAP was only accepted without a reduction of its allocation because France withdrew the NAP it submitted first and reduced its ET budget according to the EC's formula $(-14.7 \%$ or -22.9 million EUA/a).

${ }^{5}$ The NAPs submitted by the Member States together with the European Commission's decisions are available at http://ec. europa.eu/environment/climat/2nd_phase_ep.htm. For all Member States, we use figures from approved NAPs, even for those which are challenging the EC's decisions in court (Latvia, Estonia, Poland, the Czech Republic, and Hungary).

${ }^{6}$ The set of EU-12 Member States includes the new Member States which have entered the European Union in 2004 and 2007: Bulgaria, Cyprus, Czech Republic, Latvia, Lithuania, Estonia, Hungary, Malta, Poland, Rumania, Slovakia, and Slovenia. The remaining Member States will be referred to as EU-15 Member States.
}

under the EU ETS would be about $274 \mathrm{Mt} \mathrm{CO}_{2} \mathrm{e} / \mathrm{a}$ for the 27 Member States examined (see Table 1). Without the European Commission's intervention, this figure would have been significantly higher (374 $\left.\mathrm{Mt} \mathrm{CO}_{2} \mathrm{e} / \mathrm{a}\right)$. Table 1 also shows the sum of the governments' intended and companies' allowed purchases of credits from the Kyoto Mechanisms (383 $\left.\mathrm{Mt} \mathrm{CO}_{2} \mathrm{e} / \mathrm{a}\right)$. Whether companies will purchase these credits crucially depends on their costs relative to the price for EUAs which in turn depends on the stringency of the ET budgets.

\section{Stringency of ET budgets}

In order to assess the stringency of the ET budgets for phase 2, we used the following three criteria comparing the approved ET budgets to:

- The verified emissions for 2005 (excluding reserve for new entrants);

- The size of ET budgets in phase 2 (including reserve for new entrants);

- The projected emissions for 2010 (including reserve for new entrants).

Since the type and number of installations participating in the EU ETS differs between both phasese.g., as a consequence of the European Commission's attempt to harmonize the coverage of installations or because some Member States (e.g., the UK) decided to opt out installations in phase 1 -adjustments had to be made for a meaningful comparison. ${ }^{7}$ We illustrate the impact of the European Commission's assessment by applying the three stringency criteria both to the notified and the approved ET budgets.

The results for the three criteria appear in Figs. 1, 2, and 3. In each of these figures, a positive value indicates that the ET budget for phase 2 is larger and a negative value that the ET budget is smaller than the respective reference point. Figures for the EU-15 Member States are shown on the left of the bold line

\footnotetext{
${ }^{7}$ For a detailed description on the methodology, see Rogge et al. (2006).
} 
Table 2 Results for three criteria at aggregate level of 25 NAPs and comparison with companies' limit on the use of Kyoto Mechanisms

\begin{tabular}{|c|c|c|c|c|c|c|c|c|}
\hline & & \multicolumn{6}{|c|}{ ET budget in phase 2 compared to } & \multirow{3}{*}{$\begin{array}{l}\text { KM limit for } \\
\text { companies } \\
\text { In million } \\
\text { ERU-CER/a }\end{array}$} \\
\hline & & \multicolumn{2}{|c|}{ VET 2005 (criterion 1) } & \multicolumn{2}{|c|}{ ET budget in phase1 (criterion 2) } & \multicolumn{2}{|c|}{$\begin{array}{l}\text { Emission projections } \\
\text { for } 2010 \text { (criterion 3) }\end{array}$} & \\
\hline & & $\begin{array}{l}\text { In million } \\
\text { EUA }\end{array}$ & $\begin{array}{l}\text { In percent of } \\
\text { VET } 2005\end{array}$ & $\begin{array}{l}\text { In million } \\
\text { EUA }\end{array}$ & $\begin{array}{l}\text { In percent of ET } \\
\text { budget phase } 1\end{array}$ & $\begin{array}{l}\text { In million } \\
\text { EUA }\end{array}$ & $\begin{array}{l}\text { In percent of } \\
\text { projected emissions }\end{array}$ & \\
\hline \multirow[t]{2}{*}{ EU-15 } & Notified & -173.7 & -11.3 & -137.8 & -8.4 & -143.9 & -8.8 & 259.3 \\
\hline & Accepted & -232.0 & -15.7 & -205.4 & -13.1 & -211.5 & -13.5 & 222.5 \\
\hline \multirow[t]{2}{*}{ EU-12 } & Notified & 140.3 & 22.1 & 110.7 & 16.1 & 59.9 & 8.7 & 114.5 \\
\hline & Accepted & -17.7 & -3.7 & -64.2 & -12.5 & -115.1 & -22.4 & 51.4 \\
\hline \multirow[t]{2}{*}{ EU-27 } & Notified & -33.3 & -1.5 & -27.1 & -1.2 & -84.0 & -3.6 & 373.8 \\
\hline & Accepted & -249.7 & -12.8 & -269.6 & -12.9 & -326.5 & -15.7 & 273.9 \\
\hline
\end{tabular}

Source: Fraunhofer ISI based on NAPs of Member States and NAP decisions of European Commission (CEC 2006b), registry data (CITL as of October 23, 2006), UNFCCC (2006), and EEA (2006)

and for the EU-12 Member States on the right of the bold line. For comparison, the striped bars depict the results for the approved ET budgets. Aggregate figures for approved and notified NAPs are shown in Table 2.
In general, there are differences across Member States and between the groups of EU-15 Member States and EU-12 Member States, but, qualitatively, the three criteria paint a similar picture. Of the 27 approved NAPs

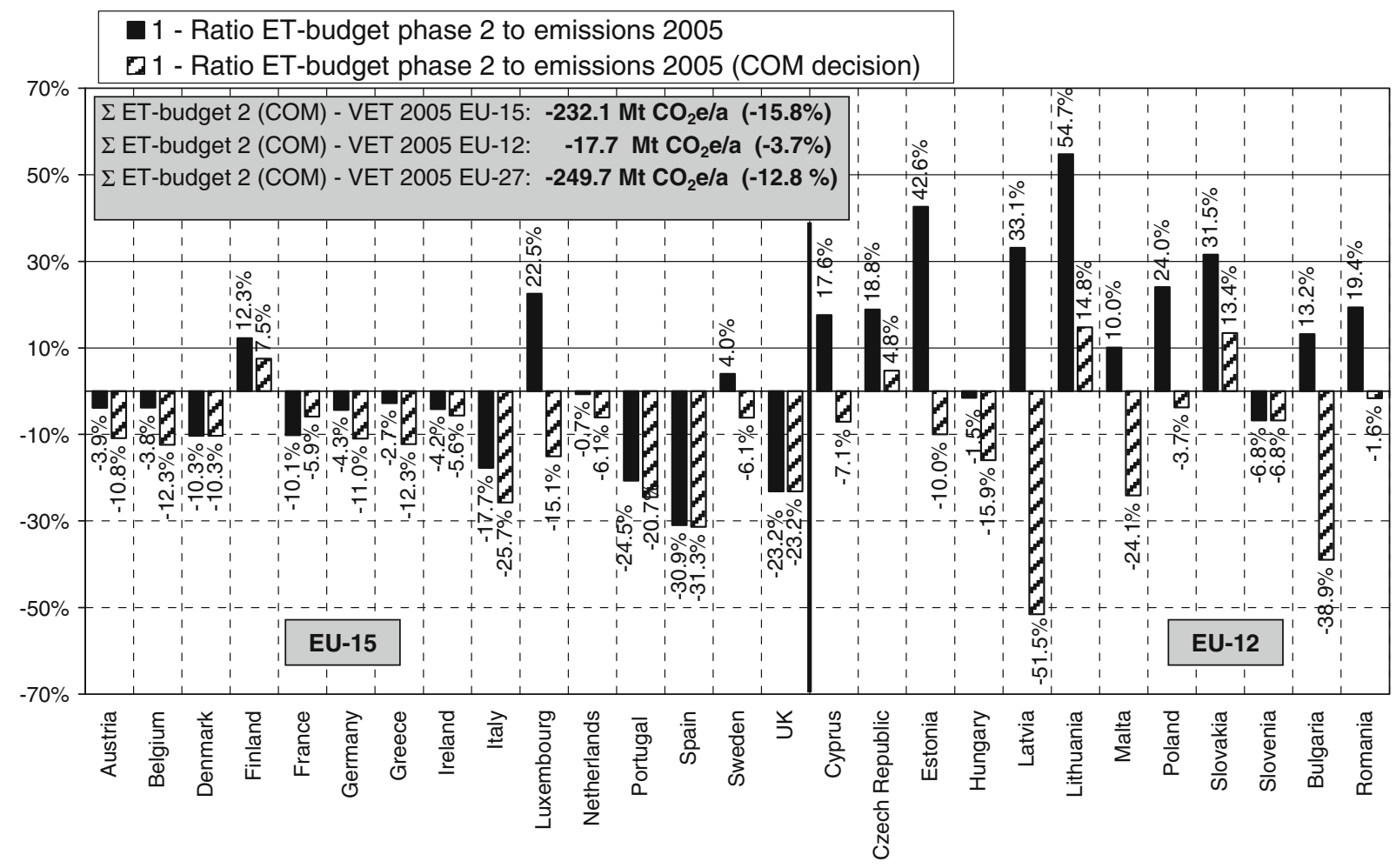

Source: Fraunhofer ISI based on NAPs of Member Statesand NAP decisions of European Commission, (CEC, 2006b), registry data (CITL as of October 23, 2006), UNFCCC (2006) and EEA (2006)

Fig. 1 ET budgets for phase 2 and COM-adjusted budgets compared to emissions in 2005 (in percent) 


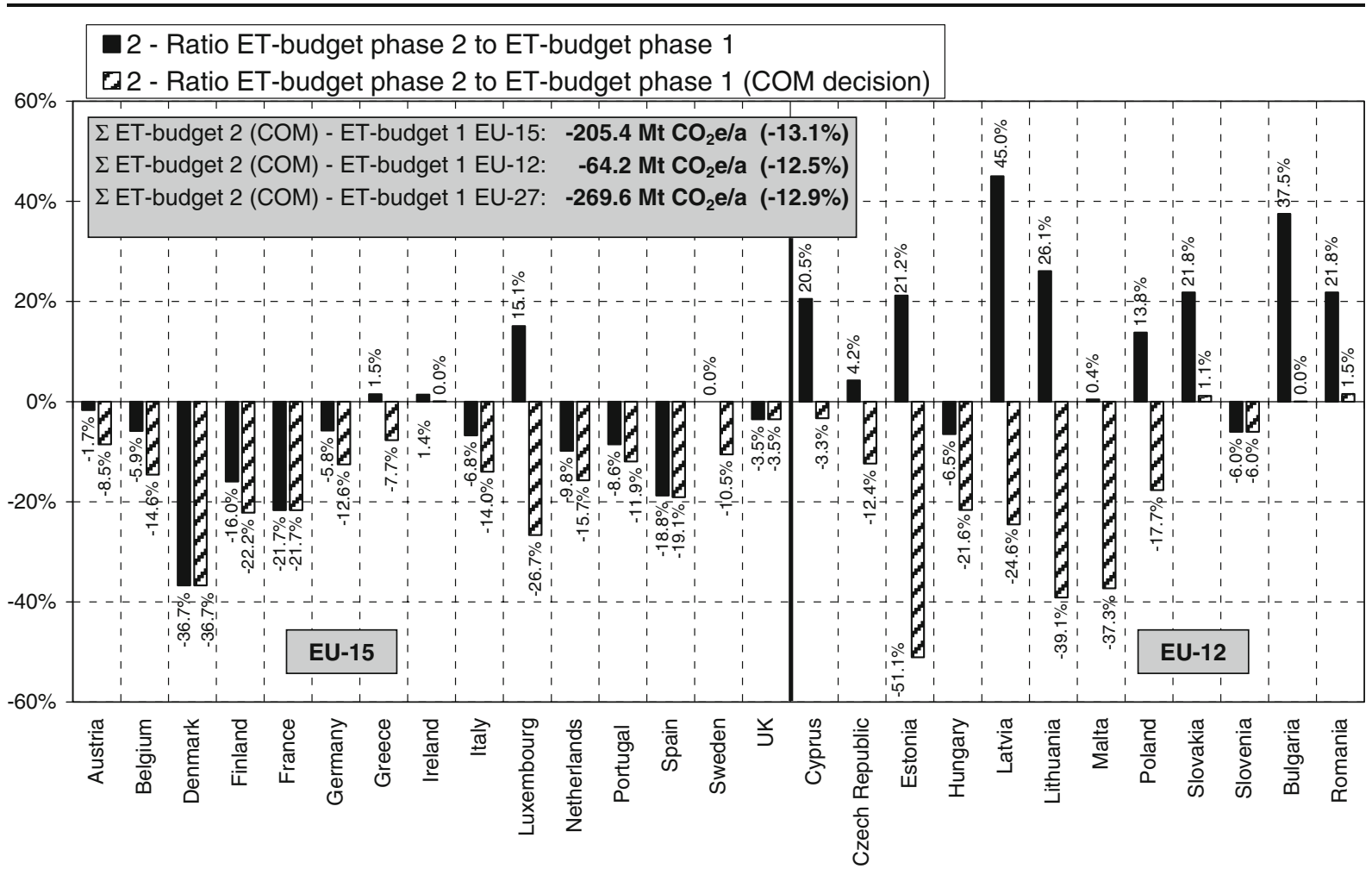

Source: Fraunhofer ISI based on NAPs of Member Statesand NAP decisions of European Commission, (CEC, 2006b), registry data (CITL as of October 23, 2006),UNFCCC (2006) and EEA (2006)

Fig. 2 ET budgets for phase 2 and COM-adjusted budgets compared to ET budgets in phase 1 (in percent)

analyzed, the vast majority now meet our three stringency criteria owing to the European Commission's budget cuts. Before the Commission's ruling though, only nine Member States fulfilled all three criteria, namely Austria, Belgium, Denmark, Ireland, Italy, the Netherlands, Spain, the UK, and-as the only EU-12 Member State-Slovenia. In particular, while the notified EU-15 ET budgets for phase 2 were much stricter than for phase 1, most notified EU-12 ET budgets appear to be rather generous. However, because of the European Commission's decisions to substantially cut several ET budgets, the EU-wide ET budget is expected to be significantly more ambitious in phase 2 than in phase 1 of the EU ETS. Our analysis suggests that, on average, the ET budgets in phase 2 are about $12.8 \%$ lower than historical emissions in $2005,12.9 \%$ lower than the budgets in phase 1 , and $15.7 \%$ lower than projected emissions in $2010 .^{8}$

\footnotetext{
${ }^{8}$ When interpreting the quantitative results, it should be kept in mind that these figures do not fully account for closures and new entrants.
}

In conclusion, the price and cost incentives to improve energy and carbon efficiency are likely to be substantially higher in phase 2 than they were in phase 1. However, the need for domestic emission reductions via improved energy and carbon efficiency in the energy and industry sectors may still be rather low. This is revealed by comparing the maximum amount of credits from the Kyoto Mechanisms that companies may use to cover their emissions under the EU ETS with the reduction requirements implied by the three criteria (see Table 2).

\section{Contribution of ET sectors versus other sectors}

In this subsection, we examine whether the macrolevel incentives for improvements in energy and carbon efficiency in the ET sectors and the other domestic sectors are cost-efficient. To do so, we assess whether the sizes of the approved ET budgets are consistent with an efficient distribution of reduction efforts between the ET sectors (energy and industry) and non-ET sectors 


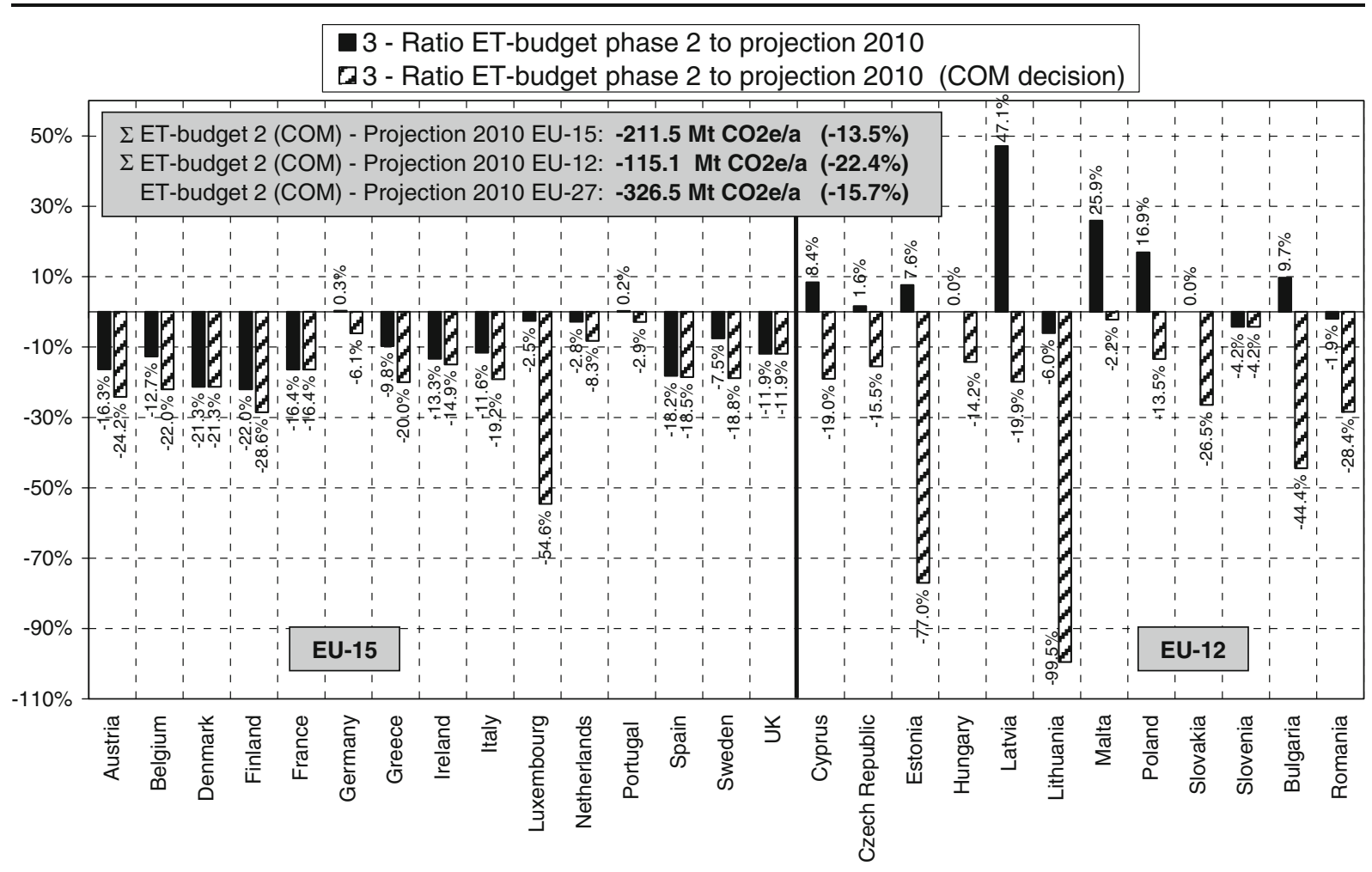

Source: Fraunhofer ISI based on NAPs of Member Statesand NAP decisions of European Commission, (CEC, 2006b), registry data (CITL as of October 23, 2006), UNFCCC (2006) and EEA (2006)

Fig. 3 ET budgets for phase 2 and COM-adjusted budgets compared to projection for 2010 (in percent)

(household, tertiary, and transport). Again, we compare these results with the budgets implied by the notified NAPs. The default economic guideline is that the size of the budgets for the ET sector and the non-ET sector should be determined such that the total abatement costs are minimized, i.e., that the marginal (social) costs of the abatement measures realized in the trading and the nontrading sectors are equal. ${ }^{9}$ Thus, sectors with cheaper measures should make a bigger contribution (relatively) to achieving a country's emission target. Ideally, marginal abatement costs should also include macroeconomic effects such as production displacement in energy-intensive sectors facing export or import competition from regions where companies' $\mathrm{CO}_{2}$ emissions are not regulated. Otherwise, for small open economies with relatively large shares of energy-intensive industries facing such international competition, this displacement effect may be large enough to warrant a redressing of the burden sharing between the ET and

\footnotetext{
${ }^{9}$ This condition then emerges from the first-order condition of the cost minimization problem for achieving a given emission target.
}

the non-ET sectors. ${ }^{10}$ However, according to many studies (including Böhringer et al. 2006; Criqui and Kitous 2003; or Peterson 2006), the marginal (social) abatement costs of the ET sector are lower than the abatement costs of other sectors in the economy (even without considering the ETS companies' option to use "cheap" credits from the Kyoto Mechanisms). ${ }^{11}$ Therefore, the ET sector should contribute more than its proportional share to the required emission reductions.

To derive a criterion for the cost-efficiency of the ET budgets, we relate the size of the ET budget in the NAPs to a "hypothetical allocation scenario between ETS and non-ETS" (see also Betz et al. 2004; or Zetterberg et al.

\footnotetext{
${ }^{10}$ In practice, such negative effects are likely to be small and limited to a few products including primary steel produced from blast oxygen furnaces, aluminum, or nitric acid (e.g., Peterson and Schleich 2007; Hourcade et al. 2008).

${ }^{11}$ These results were obtained for lower fuel prices than currently observed. Arguably, substantially higher fuel prices may lead to a different outcome since they tend to raise the costs for abatement measures available particularly in the ET sector (e.g., fuel switch).
} 
2004). To calculate this hypothetical allocation scenario, we multiply a Member State's burden sharing or Kyoto target by the share of the ET sector's $\mathrm{CO}_{2}$ emissions relative to total greenhouse gas emissions (using the data from the national inventories (UNFCCC 2006)). Thus, the hypothetical allocation scenario represents the budget resulting for the trading sector (biggest parts of energy and industry) if all sectors contributed proportionally to achieving a country's emission target. Accordingly, if the ET budget of a Member State was found to be higher than the emission budget in the hypothetical allocation scenario, a Member State could achieve its Kyoto target at lower total abatement costs by lowering the size of the ET budget and, at the same time, increasing the amount of emissions allowed in the non-ETS sectors.

Our analysis also accounts for Member States' intended use of credits from Kyoto Mechanisms, thereby increasing the national emission budgets (and consequently also the hypothetical allocation scenario). In our assessment, the NAP of a Member State is considered to meet this criterion if the ET budget is not larger than the budget which corresponds to the hypothetical allocation scenario.

Figure 4 shows the differences between the actual ET budgets and the hypothetical allocation scenario (in percent), again comparing the ET budgets accepted by the European Commission with the ET budgets notified by the Member States. Before the Commission's ruling, the emission budgets for the ET sectors in most Member States were - often significantly-larger than those which would result from a proportional contribution. The striped bars illustrate how the European Commission's decisions on the NAPs have improved the costefficiency of the ET budgets for phase 2 budgets: Almost all of the 27 Member States are now requested to assign EU ETS budgets that are close to or even clearly below the hypothetical allocation scenario.

To sum up, from a cost-efficiency perspective, the notified ET budgets would have resulted in far too little improvement in energy and carbon efficiency in the ET sectors in most Member States. Thus, without the European Commission's intervention, other sectors like

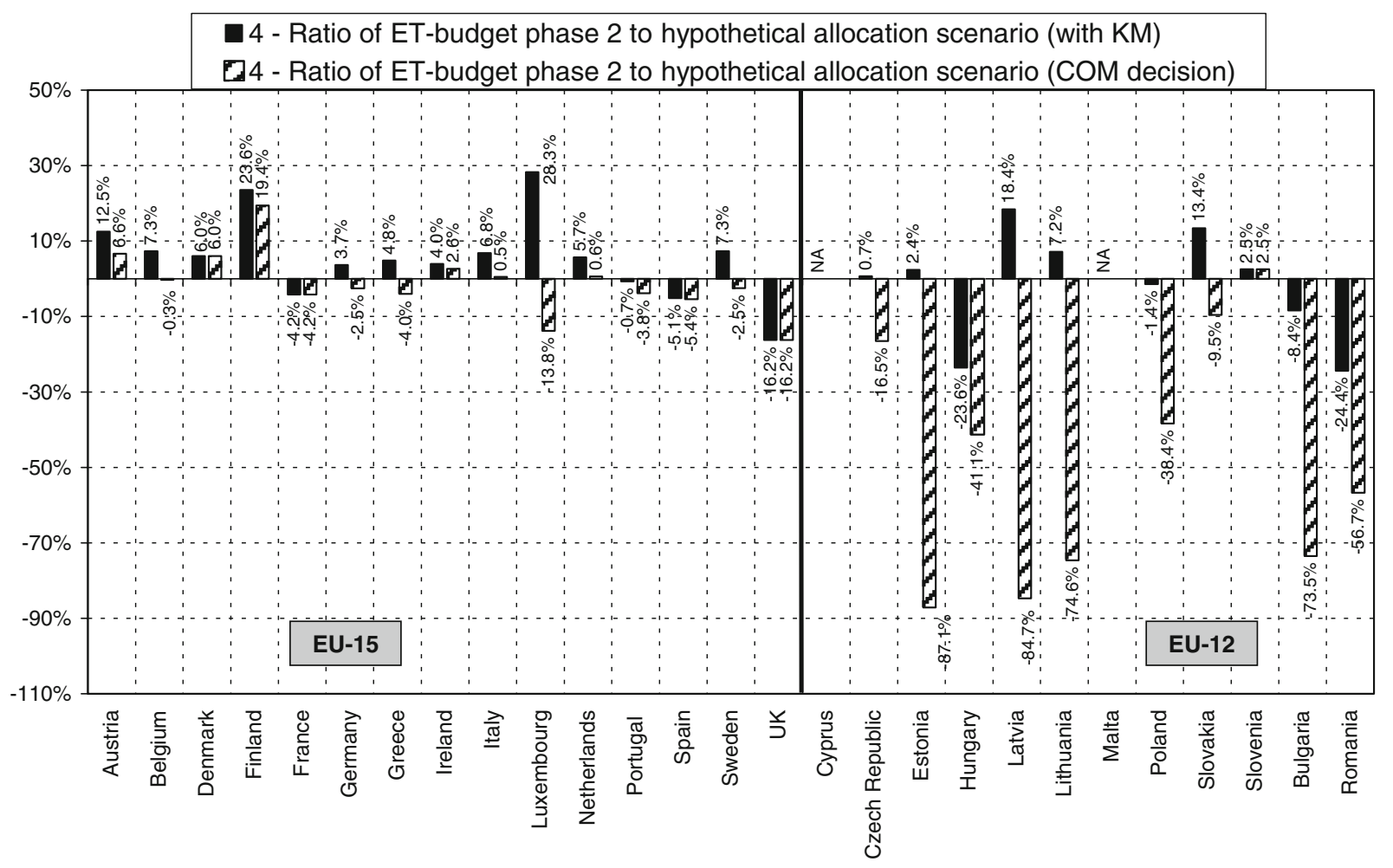

Source: Fraunhofer ISI based on NAPs of Member Statesand NAP decisions of European Commission,CEC 2006b, registry data (CITL as of October 23, 2006), UNFCCC 2006 and EEA 2006

Fig. 4 ET budget for phase 2 compared to "hypothetical allocation scenario" with Kyoto Mechanisms (in percent) 
buildings and transportation would have had to achieve greater reductions - arguably including also greater improvements in energy efficiency-for the national Kyoto targets to be met.

\section{Incentives for energy efficiency at the microlevel}

At the microlevel, we assess the observed allocation rules for existing and new installations primarily based on economic theory. In particular, we focus on the incentives given by these rules for energy and carbon efficiency.

Auctioning versus free allocation

for existing installations

Allowances may be allocated free of charge or sold at an auction. In general, economists prefer auctioning to a gratis allocation (e.g., Cramton and Kerr 2002). Under auctioning, the "polluter-pays" principle holds so that the outcome may be perceived as "fair." Auctioning off allowances would also address "windfall profits": If companies manage to pass on any additional marginal costs (opportunity costs) associated with emissions (i.e., price of allowances) to customers, extra profits (producer rents or "windfall profits") accrue if allowances are allocated for free. In addition, auction revenues could be used for other purposes, including funding for $\mathrm{R} \& \mathrm{D}$ or investment in energy- and carbon-efficient technologies. Further implications of auctioning for energy efficiency are discussed in more detail below.

\section{Incentives for replacement}

When deciding on the timing for the replacement of an installation, companies need to consider the (opportunity) costs for covering carbon emissions for the existing installation. If closing the old plant does not alter its allocation, the incentives for replacement are identical under free allocation and auctioning (e.g., Åhman et al. 2007). A closure would then allow a company to sell the entire (free) allocation (and possibly save expenses that might have been incurred for purchasing additional allowances to cover all the emissions from the old plant). If allowances are allocated for free, the revenues from selling allowances (plus expenses saved from not having to purchase additional allowances) are identical to the expenses for purchasing allowances if allowances are auctioned off. However, since in most Member States closures lead to a termination of allocation, the incentives to replace old installations in the EU ETS are stronger under an auctioning scheme than they are under free allocation.

\section{Updating of base period}

If allowances are allocated for free and if future (arguably tighter) allocation depends on today's emissions (updating), the marginal costs of energy efficiency projects increase by the (opportunity) costs resulting from lower allocation in future trading periods (see also Neuhoff et al. 2006). Thus, updating the base period distorts companies' incentives to reduce emissions because future allocations will be lower. As a consequence, updating results in reduced incentives to invest in carbon and energy efficiency for installations covered by the EU ETS.

\section{Carbon cost pass through in the power market}

Higher product prices resulting from the pass through of carbon costs translate into stronger incentives for energy efficiency on the demand side. The extent to which product prices increase when carbon emissions are costly depends, in particular, on the responsiveness of demand and on international competition. In the power sector, demand is rather inelastic (at least in the short run)-indicating that higher power prices alone do not directly lead to electricity savings - and international competition is low (at least from outside the EU). In general though, whether allowances are auctioned off or allocated for free does not alter the opportunity costs (of additional emissions). From this perspective, the extent of the pass through of carbon costs to electricity prices which eventually determines incentives for energy efficiency on the demand side should be identical under auctioning and gratis allocation in liberalized competitive electricity markets. Of course, the distributional effects on utilities' profits are quite different.

\section{Impact of market regulation and structure}

If power markets were regulated, as is for example the case in some US states, the impact of emissions trading 
on power prices would be negligible under free allocation. In this case, average costs would only increase to the extent that additional allowances needed to be purchased if the free allocation were smaller than actual emissions (e.g., Burtraw et al. 2006). By the same token, auctioning would result in higher product prices and higher incentives for energy efficiency on the demand side. Depending on the price-setting mechanism, incentives may also differ across customer groups. For example, under Ramsey pricing, customer groups with a lower price-elastic demand for electricity would face higher price increases and incentives for energy efficiency than customer groups exhibiting a higher price-elastic demand. ${ }^{12}$

In liberalized power markets, price increases should not depend on whether allowances are auctioned off or allocated for free, unless companies refrain from passing through opportunity costs under free allocation because they fear this might have regulatory consequences. It is not possible to determine whether emissions trading results in higher prices under perfectly or imperfectly competitive product market conditions without knowing the shape of the demand curve (e.g., Sijm et al. 2005). For example, under imperfect competition, the carbon cost pass through is lower for a linear demand function and higher for an isoelastic demand function than it is under perfect competition. ${ }^{13}$

In contrast, if there is imperfect competition on the market for emission allowances, auctioning may result in lower power prices and thus lower incentives for energy efficiency on the demand side. Under free allocation, power companies have an incentive to exert market power to support a high price of allowances in order to charge a higher price for their entire electricity production and increase profits (Ehrhart et al. 2008). ${ }^{14}$ For companies which have to pay for their allowances, this incentive is lower, resulting in lower power prices and lower incentives to improve the demand-side energy efficiency.

\footnotetext{
${ }^{12}$ In general, Ramsey pricing refers to a linear pricing scheme designed for a multiproduct natural monopolist, which maximizes social welfare while allowing the monopolist sufficient profits to cover total costs. Ramsey pricing then implies prices above marginal costs in inverse proportion to the elasticity of demand (see Ramsey 1927).

${ }^{13}$ For an isoelastic demand function, the pass through rate will be more than one since, for example, an increase in costs by $10 \%$ would also result in a $10 \%$ increase in the power price.
}

\section{Diffusion effect}

To assess the effects of allocation on carbon and energy efficiency, the adoption and diffusion of new technologies also have to be taken into account. The adoption of more energy-efficient technologies reduces emission costs for the investor because the freed-up allowances can be sold on the market or because fewer allowances need to be purchased at auction. This effect is the same, independent of whether allowances are allocated free of charge or auctioned off. But there are differences once the diffusion of new technologies is taken into account. The diffusion of more energy-efficient technologies decreases the demand for allowances relative to supply, and so the market price decreases. If allowances are allocated for free, this diffusion effect means that the freed-up allowances will generate less revenue for the investor. In contrast, if allowances are auctioned off, the investor benefits in the long run because of the reduced allowance price (see Milliman and Prince 1989). By this token, incentives for innovation and energy efficiency are higher under auctioning than under free allocation. Whether diffusion actually leads to lower allowance prices depends on whether the regulator adjusts the target accordingly. A reduction in the ET budget over time will counterbalance the effect of diffusion on the allowance price. In this case, the differences between grandfathering and auctions relating to innovation vanish. ${ }^{15}$

\section{Early price signals and planning reliability for investment}

Auctioning off part of the budget right at the beginning of the trading period may generate robust early price signals that reflect the scarcity of allowances in the market since participants base their bidding behavior on their marginal abatement costs (and expected prices in the secondary market; e.g. Schmalensee et al. 1998; Ehrhart et al. 2005). Such improved price signals may

\footnotetext{
${ }^{14}$ The observation that the price for EUAs in the (rather thin) spot market did not drop to zero but instead remained around or above 10 to $15 €$ per EUA once the number of surplus allowances became common knowledge in May 2006 is consistent with this interpretation.

${ }^{15}$ In fact, a clear ranking of environmental policies (emissions trading, environmental taxes, standards, emission rates) in terms of innovation is not possible once technology spillovers, market structure, or the regulator's response to diffusion are taken into account (see Fischer et al. 2003; or Requate 2005).
} 
raise the investment security for carbon- and energyefficient technologies. To avoid a possible bias in the price signal, auctions should be two-sided, i.e., companies should not only be allowed to purchase but also to sell allowances (from primary free allocation). If only the government were allowed to sell allowances, the auction price might be biased upwards (compared to the "true equilibrium price") because companies with cheap abatement measures and excess allowances would not be able to participate as sellers. Finally, if the auctioning share were sufficiently large, governments could auction off appropriate numbers of allowances to cushion price volatility or to set a price floor (Hepburn et al. 2006). This would improve the planning reliability for investments in energy efficiency because the uncertainty about payoffs would be lower and profits could be higher.

In brief, the main findings from the (primarily) theoretical literature presented in this subsection suggest that auctions tend to be associated with higher innovation effects than the typical grandfathering, where allowances are allocated free of charge based on historical emissions. Allocating allowances for free, however, is politically more palatable since the costs for companies directly covered by the EU ETS are lower. ${ }^{16}$

\section{Outcomes for phase 2}

The directive allows Member States to auction off up to $5 \%$ of the ET budget in phase 1 and up to $10 \%$ in phase 2 . Compared to phase 1, where only four Member States (Denmark, Hungary, Ireland, and Lithuania) chose to auction off parts of their ET budget, more Member States (so far nine Member States) intend to do so in phase 2 (but not Denmark). However, the shares to be auctioned tend to be well below the maximum share of $10 \%$ allowed by the ETS Directive in phase 2. While in phase 1 the total auction share in the EU ETS was only around $0.2 \%$, in phase 2 it will be about $3.1 \%$ of total allocation,

\footnotetext{
${ }^{16}$ See also Bovenberg and Goulder (2002) and Bovenberg et al. (2005), who empirically and theoretically analyze the adverse distributional effects of auctioning emission allowances for emission-related industries. By the same token, profit losses of these industries may be avoided through the free allocation of emission allowances. However, the higher the abatement requirements, the higher is the efficiency costs of such compensating policies because they force the government to forego auctioning revenue and - in the absence of lump-sum taxation - to rely more heavily on regular distorting taxes.
}

a figure which is mainly driven by the high level of auctioning in Germany and the UK. As was already the case in phase 1, no Member State considered early auctions to provide early price signals in phase 2 .

As can be seen from the "Appendix," most Member States allocate allowances to existing installations for free based on historical emissions. Also, most Member States use data from the year 2005 (updating) to determine the number of EUAs to be allocated to individual installations (through base periods extending to 2005). One reason for this violation of the guidance provided by the EC (CEC 2005) may be that verified emissions data at the level of installations were readily available for 2005 .

Thus, the low auctioning share in phase 2 is unlikely to substantially advance energy efficiency via improved incentives for replacing inefficient technologies, early price signals, or the diffusion effect. Likewise, updating may have resulted in reduced energy efficiency in phase 1 and - if participants expect updating for future periods to continue - may also bias companies' investment decisions against energy efficiency.

Since prices for EUAs are expected to be higher than in phase 1, the pass through of carbon costs will result in stronger incentives for the demand-side energy efficiency in phase 2 of the EU ETS - independent of whether allowances are allocated for free or auctioned off. According to the study by Sijm et al. (2006) for selected EU Member States, the pass through rates for wholesale electricity prices vary between $60 \%$ and $100 \%$, depending on the country, market structure, demand elasticity, load type (base and peak load), and $\mathrm{CO}_{2}$ price considered. Similarly, Honkatukia et al. (2006) found average pass through rates for Finland of $75 \%$ to $95 \%$. Both studies find evidence that pass through rates are lower for base load than for peak load. One possible reason is that nonfossil generation technologies compete with fossil fuel technologies more effectively at low loads so that fossil fuel technologies would risk losing all the market if they passed on $100 \%$ of the costs (Reinaud 2007). Similarly, because of start-up costs, power stations may prefer to operate during offpeak periods (Sijm et al. 2006). As a consequence, additional incentives for energy efficiency may be distributed asymmetrically across customer groups. In addition, since the additional costs for carbon may - in some power markets - affect the merit order of peak and off-peak technologies (see, for example, Keats and Neuhoff 2005), the price difference for peak and off- 
peak demand may change. Such a change would also alter demand-side incentives, e.g., for load management measures.

Based on a review of the scarce literature available so far on this topic, a recent study by the International Energy Agency concludes that "there is no universal answer on how the EU ETS has affected electricity prices" (Reinaud 2007, p. 6). First, there is no single EU electricity market but several market and regulatory frameworks across the EU Member States. In particular, not all electricity prices in Europe are set on the wholesale market (e.g., via power exchanges). In fact, the bulk of electricity is traded through longterm (financial or physical) contracts, where the effects of wholesale prices are probably only indirect. Second, since there are no data available on companies' bidding strategies or on marginal suppliers to the market, the exact level of carbon cost pass through to the electricity price cannot be determined. Finally, besides carbon prices, many other factors affect generation prices including high natural gas prices or the influence of market power in the power market.

Conventional grandfathering and benchmarking for existing installations

Under benchmarking, allocation is based on specific emission values per unit of production (e.g., kilogram of $\mathrm{CO}_{2}$ per megawatt hour electricity or ton of $\mathrm{CO}_{2}$ per ton of cement clinker) for a particular group of products or installations. The actual number of allowances can be derived from the specific benchmark multiplied by past or predicted installation-specific or standardized activity rates. Average benchmarks are calculated as the activity-weighted average of emission values for a particular group and result in a higher allocation for all companies than benchmarks based on the best available technology (BAT benchmarks). ${ }^{17}$ Benchmarking favors carbon-efficient installations over less carbonefficient installations since operators of the latter installation need to purchase missing allowances on the market or have fewer excess allowances. There are various reasons why benchmarking allocation may be

\footnotetext{
${ }^{17}$ This reasoning implicitly assumes that the budget for installations receiving a benchmarking allocation is not fixed. If the budget were fixed, allocation would be independent of the benchmark level because a compliance factor would be applied to exactly balance the budget. In this case, allocation to an installation would correspond to that installation's activity rate share.
}

preferable to allocation based on historical emissions. First, since benchmarking favors installations with low emission values and accounts for early action, the allocation outcome is perceived as "fair." Second, compared to conventional grandfathering, benchmarking provides reduced incentives for companies to act strategically when there is "updating" (see also Sterner and Muller 2006) because allocation is not based on an individual installation's emission value. As a result, the operators' incentives to behave strategically to affect the future endowment of EUAs are limited and disincentives for improved energy and carbon efficiency are reduced. In terms of energy efficiency, benchmarking provides a greater incentive to replace old, inefficient installations than conventional grandfathering, if - as is usually the case for the EU ETS in most Member States - closures lead to a termination of allocation (Cremer and Schleich 2006). These incentives are similar to the incentives for replacement provided by auctioning but not as strong.

\section{Outcomes for phase 2}

Several countries like Austria, Belgium, Denmark, Germany, Italy, Latvia, Spain, Sweden, and the UK base allocation for some existing installations - mostly power installations — on benchmarks (see "Appendix"). Typically, these benchmarks are further differentiated by fuels and technologies. ${ }^{18}$ Apart from France and Denmark, these countries did not use benchmarks to allocate EUAs to existing installations in phase 1.

Thus, the increased use of benchmarks for allocating allowances to existing installations compared to phase 1 can be expected to accelerate the replacement of old carbon-intensive existing technologies which should increase the energy efficiency of installations covered by the EU ETS.

\section{Allocation rules for new projects}

The logic of emissions trading requires that all the allowances for new projects (i.e., new installations and capacity extensions of existing installations) be pur-

\footnotetext{
${ }^{18}$ The Netherlands, Flanders, and Wallonia, where allocation is based on covenants or voluntary agreements, use BAT benchmarks for existing installations. However, as in phase 1, they use benchmarks to calculate the efficiency factor (i.e., difference between BAT and actual efficiency) which is used in the allocation formula (see "Appendix").
} 
chased at market prices since investment decisions can then be based on the full social costs covered by the scheme (i.e., private costs plus environmental costs). Allocating allowances for free to new projects amounts to subsidizing investments (overcapacity) and output (Spulber 1985; Ellerman 2008; Åhman et al. 2007) and distorts the incentives for investing in less carbonintensive technologies in the long run (Betz et al. 2004; Matthes et al. 2005; Neuhoff et al. 2006). In the power sector, for example, these subsidies lead to lower power prices and reduced incentives to improve demand-side energy efficiency, ceteris paribus. Likewise, basing the allocation to new projects on BAT values for individual installations or on BAT benchmarks for homogenous products or processes where the benchmarks are further differentiated by fuel types or technologies implies subsidization of particular technologies. Such differentiation further reduces the cost-saving potential of emissions trading schemes because innovation incentives are then limited to the subgroups. In contrast, if companies had to purchase all the allowances for new projects, they would have strong incentives to implement energy-efficient, lowcarbon technologies because these technologies do not require as many allowances. ${ }^{19}$

\section{Outcomes for phase 2}

While the commission would have preferred newcomers to purchase allowances on the market (CEC 2003b), in all Member States, new projects receive allowances for free from a new entrants' reserve in phase 1 and in phase 2. Allocation typically occurs on a first-come-first-served basis. Only power plants in the Swedish power sector will have to buy all their allowances on the market. As in phase 1, gratis allocation in most Member States is typically based on BAT values for individual installations or on BAT benchmarks for homogenous products (or technologies). BAT benchmarks are common in the energy sector, where they tend to be differentiated by fuel inputs. So far, only Denmark, Luxembourg, Sweden, Flanders, and Wallonia in Belgium and the UK are applying uniform benchmarks, which give clearer

\footnotetext{
${ }^{19}$ However, under the current closure rules, which essentially provide an output subsidy to incumbent installations (see below), free allocation to new entrants may be considered second best because it counters the bias against closure ( $\AA$ hman and Holmgren 2006).
}

incentives to invest in the most carbon- and energyefficient technology than differentiated benchmarks. To speed up the diffusion of new combined heat and power plants, some Member States are applying a "double benchmark" for heat and electricity (e.g., Belgium, Germany, Italy, Ireland, Latvia, Lithuania, Luxemburg, Poland, and Slovenia). If BAT benchmarks are used for new projects in industry sectors, they tend to be technology-specific and often assume gas as the fuel input (e.g., Latvia, UK). Sometimes, product groups are further split into subgroups (e.g., different types of tiles or glass in Germany). So far, empirical results on the effects of free allocation to new entrants are scarce. Findings for Denmark, where capacity is used as the activity rate, imply that this allocation rule has indeed led to investments in overdimensioned boilers (Danish Ministry of the Environment 2007).

In sum, the current allocation rules for new projects tend to be detrimental to carbon and energy efficiency for two main reasons. First, allocating allowances for free amounts to subsidizing output which in turn leads to lower product prices and - in case of electricity - to reduced incentives for demand-side energy efficiency. Second, benchmark differentiation (for demand- and supply-side technologies) fails to provide the optimal incentives for developing and adopting the most energy- and carbon-efficient technologies.

\section{Allocation rules for closures}

From an economic perspective, closures of installations should not alter their allocation. In contrast, if allocation is terminated after closure, companies do not properly account for the true opportunity costs. Since they lose the allocated allowances, the costs to the company of closing an installation are higher than the socially optimal costs. As a consequence, old plants may continue to be operated too long and new investments may be postponed (Spulber 1985; Åhman et al. 2007). In terms of energy efficiency, this inhibits the diffusion of energy-efficient technologies. Stopping allocation because of closure corresponds to an output subsidy, and consequently there will be too many companies (and inefficient installations) in the market. As is typically the case in other cap-and-trade systems (e.g., Ellerman et al. 2003), operators should continue to receive the intended quantity of allowances even after closure. In contrast, in both phases of the EU ETS, most Member States decided to end the 
distribution of allowances with the year an installation closes. Arguably, the main reason is that Member States were concerned that operators might shut down installations, keep the allocation, and open a new plant in another country. Another reason is that Member States linked existing operating permits with the permit to emit greenhouse gases (see Betz et al. 2006a). Consequently, allocation has to stop once the operation permit ceases to apply. For phase 2, Cyprus, Flanders, and Malta, among others, joined Greece, Hungary, Luxembourg, the Netherlands, Poland, and the UK, which continue to include a so-called transfer rule for new installations replacing closed installations.

\section{Conclusions}

The concluding section summarizes the main results, provides guidance for the future design of the EU ETS (and possibly other emission trading schemes), and relates the main findings of the paper to the recent proposal by the European Commission for a new directive governing phase 3 (2013-2020) of the EU ETS (CEC 2008a).

\section{Macrolevel}

Our analysis at the macrolevel suggests that, on average, ET budgets for phase 2 are about $12.8 \%$ lower than historical emissions in 2005, $12.9 \%$ lower than the budgets in phase 1 (2005-2007), and 15.7\% lower than projected emissions in 2010. Thus, the ET budgets for phase 2 are much stricter than for phase 1 . Consequently, prices for EUAs are expected to be higher and the incentives to improve carbon efficiency as well as primary and end-use energy efficiency should be stronger in phase 2 than in phase 1. Prices for EUAs for phase 2 of currently around $20 €$ support this view. The tighter budgets for phase 2 are primarily the outcome of the European Commission's decision to substantially cut the ET budgets in the notified NAPs rather than the result of Member States' efforts to curtail greenhouse gas emissions using the EU ETS. The adjustments imposed by the European Commission also lead to a more cost-efficient split of the required reduction efforts between the ET sectors and other sectors. For most countries, the improvements in carbon and energy efficiency which are implicit in the accepted ET budgets in the ET sector should result in lower overall costs than the budgets in the notified NAPs. However, our analysis shows that reduction requirements in the ET sectors may still be limited as companies (and governments) are permitted to use substantial amounts of credits from the Kyoto Mechanisms. Eventually though, the extent to which these credits will be used by companies depends on the prices for EUAs (including expected prices for phase 3) and for credits from Joint Implementation and Clean Development Mechanism projects.

By applying a harmonized rule, the European Commission's decisions on the size of the ET budgets effectively imply a centralized setting of the cap. Similarly, according to the European Commission's proposal for phase 3, the future EU ETS will no longer require National Allocation Plans. Instead, there will be an EUwide cap which corresponds to a reduction of $21 \%$ in 2020 compared to 2005 emissions. To achieve the European Union's greenhouse gas emission reduction target of $20 \%$ by 2020 compared to 1990 emission levels (or 14\% compared to 2005 levels), the aggregate reduction target for the non-ETS sector in the EU 27 is $10 \%$ for 2020 compared to 2005 emission levels. To determine the size of the ET budget for each year in phase 2, the average ET budget of all Member States in phase 2 will be reduced linearly by $1.74 \%$ from 2010 on. Unlike the EU-wide ET budget, the target for the nonETS sector is further broken down into individual nonETS sector targets for Member States. These range from reductions of $20 \%$ for Ireland, Denmark, and Luxembourg to increases of $19 \%$ and $20 \%$ for Rumania and Bulgaria, respectively. According to the proposed directive, the reduction targets for the ET sector and the non-ET sector correspond to a cost-efficient split of the overall reduction burden in the EU. Thus, the EU ETS can be expected to provide improved incentives for costefficient carbon and energy efficiency for the ETS and non-ETS sectors in the future. The use of Kyoto Mechanisms will be limited in the sense that companies may transfer any unused part of the credit limits from phase 2 into phase 3. According to the proposed directive, credits from projects which reduce greenhouse gas emissions in non-ETS sectors could also be used to cover EU ETS emissions if they meet certain criteria, e.g., no double-counting of emission reductions. Having been debated for quite a while as "domestic offset projects," this supplementary flexibility mechanism now termed "community-level projects" could provide additional financial incentives for investments in energy efficiency outside the EU ETS sector (Betz et al. 2006b). 
Further, phase 3 is scheduled to last for 8 years (2013-2020) rather than five. In addition, the linear factor of $1.74 \%$ will be applied to determine the size of the ET budget until 2025 unless a review by the European Commission states otherwise. Compared to the reduction path implied by the ET budget for phase 2 (12.9\% compared to 2005 emissions), the ET budget for phase 3 seems to be less stringent. The proposed new directive also provides some flexibility: Once an international Post-Kyoto agreement is reached, the ET budgets and the targets for the non-ETS sectors will be adjusted, and the increased use of credits from the Kyoto Mechanisms in phase 3 will be permitted. Since longer phases better match companies' investment cycles and reduce uncertainty about the profitability of new investments, they are likely to increase the diffusion and development of carbon- and energy-efficient technologies. Longer phases, however, also limit the system's flexibility to react to unexpected developments, such as technological breakthroughs, sudden changes in climate policy, or improved knowledge about the causes and effects of climate change. To address this tradeoff, the proposals of the States (National Emissions Trading Taskforce 2006) and the former Howard government (Prime Ministerial Task Group on Emissions Trading 2007) for an Australian ETS includes the setting of ET budgets together with upper and lower bounds for future budgets. These gateways are subject to regular reviews. As an alternative, Ismer and Neuhoff (2006) propose that governments issue put options on the price of allowances. Such options would give investors in energy efficiency the right, but not the obligation, to sell allowances to the government at a predetermined (strike) price. Such provisions would improve planning stability without compromising flexibility at the macrolevel.

Intertemporal flexibility of the ETS is also determined by banking rules. Unlike the first phase, the transfer of leftover EUAs into future phases will no longer be restricted. Allowing banking is expected to accelerate the diffusion of energy-efficient technologies if future prices for EUAs are high compared to current mitigation costs. However, since the transferred allowances may be used to cover emissions in the future, banking may slow down energy efficiency in later phases (Phanaeuf and Requate 2002).

To sum up, future allowance prices are expected to be substantially higher than in phase 1 resulting in stronger cost and price incentives for carbon and energy efficiency in installations in the ETS sector. To the extent that companies from these sectors (notably power producers) pass through the extra costs for carbon, higher prices for allowances also translate into stronger incentives for demand-side energy efficiency. However, cost and price incentives may not be sufficient to overcome market failures and other barriers to energy efficiency such as information and other transaction costs, split incentives (landlord-tenant problem), or bounded rationality on the part of the investors. These barriers may prevent energy efficiency measures from being realized, even when they are cost-efficient under current economic conditions (e.g., Jaffe and Stavins 1994a, b; Brown 2001; Ostertag 2003 or Sorrell et al. 2004). As a consequence, additional policies will have to be implemented to trigger sufficient improvements in end-use energy efficiency (e.g., Bertoldi et al. 2005). For small- and medium-sized companies and the public sector, measures to overcome these barriers include (but are not limited to) contracting via energy services companies, implementing energy management systems, promoting public-private energy efficiency funds, or financing packages and energy audits. Similarly, for the household sector, building codes, labeling and minimum energy performance standards for appliances, or tradable white certificate schemes may be suitable measures to overcome these barriers (see also CEC 2006d). Such demand-side measures will also reduce emissions from EU ETS installations such as large power and heat plants and reduce prices for EUAs, ceteris paribus. These effects are likely to differ across load types and energy companies and they may also change breakeven points for conversion technologies.

\section{Microlevel}

Within the constraints of the EU ETS directive, Member States were given the opportunity to alter allocation rules at the microlevel between phases 1 and 2 in order to incorporate lessons learnt during the first phase. Comparing the allocation rules between phases 1 and 2 shows mixed results in terms of increased incentives for carbon and energy efficiency with substantial differences across Member States. A general "path dependency" of allocation rules can be observed, i.e., Member States tend to keep the allocation concepts and methodologies applied in phase 1. Improvements in terms of carbon and energy efficiency include an increase in auctioning and the increased application of benchmarks 
for existing and new energy installations, in particular in the power sector in EU-15 Member States.

Even though the share of allowances to be auctioned in phase $2(3.1 \%)$ is higher than in phase $1(0.2 \%)$, it still falls considerably short of the maximum level of $10 \%$ permitted by the directive and cannot be expected to have substantial effects on innovation. According to the directive proposal by the EC, full auctioning should be the rule for the power sector starting in 2013. For industrial installations participating in the EU ETS, there should be a gradual transition towards full auctioning in 2020 starting with free allocation of $80 \%$ of their share in 2013 . However, possible exceptions via free allocation or via tax adjustments for imports and exports at the border are foreseen for installations in sectors which are exposed to a significant risk of carbon leakage ${ }^{20}$. A decision on such a measure will be made by 2011 . So, initially, about two thirds of all allowances would be auctioned off in phase 3 (CEC 2008a). For nonpower installations (and for heat generated by CHP plants), the transitional free allocation is scheduled to be based on harmonized EU allocation rules, such as EU-wide BAT benchmarks, but the exact rules may not be known until 2011. Thus, for power installations and - depending on the extent of benchmark differentiation - also for nonpower installation, the future allocation rules in the EU ETS can be expected to provide stronger incentives to replace inefficient technologies. In addition, the new directive may indirectly spur innovation in energy efficiency since $20 \%$ of the revenues from auctioning shall be used, among other things, for research and development in energy efficiency.

Similarly, the observed increase between phase 1 and phase 2 in the use of benchmarks and standard utilization rates for allocation to new projects improves efficiency compared to using installation-specific emission values. These are still the dominant rule in new Member States even though operators continue to have an incentive to predict "optimistic" activity rates as was the case in phase 1 (Grubb and Ferrario 2006). Nevertheless, benchmarks which are differentiated by fuels, technologies, or activity rates distort dynamic innovation incentives. The directive proposal for phase 3 requires harmonized allocation rules for new projects in order to

\footnotetext{
${ }^{20}$ Total emissions may increase if production is displaced to regions where companies are not subject to climate policy regulations and where production is more carbon-intensive than in the EU.
}

level the playing field and to overcome a possible prisoners' dilemma situation resulting from Member States' strategic incentive to attract new projects through favorable allocation. Also, incumbent installations and new entrants are to be treated alike. Accordingly, new power installations will not receive free allowances and the allocation to new nonpower installations should be the same as for existing nonpower installations. Thus, power production will no longer be subsidized, and - to the extent that old installations and the new ones replacing them receive the same allocation-incentives to close installations are no longer distorted.

To sum up, the incentives for carbon and energy efficiency generated through the EU ETS have significantly improved at the macrolevel, but only slightly at the microlevel between phase 1 and phase 2. The European Commission's proposal for phase 3 implies increased incentives for carbon and energy efficiency, in particular at the microlevel. The actual effects will depend on the final outcome of the policy-making process which includes the Council and the European Parliament and on the detailed allocation rules for industry installations. From a carbon and energy efficiency point of view, these rules should be guided by uniform BAT benchmarks during the transition to full auctioning. Since provisions for the new category of "community-level projects" allow companies to use credits from domestic projects in the non-ETS sectors to cover their emissions, abatement efforts and costs between the ET- and the non-ET sectors will be linked. Thus, these projects may represent an additional channel for improved incentives for energy efficiency via the EU ETS.

Finally, while the analysis presented in this paper is - to a large extent-confined to a comparison between "economic theory" and "observed rules in the EU ETS," future research may link "economic theory," "observed rules," and "observed outcomes". Such analyses would make it possible to assess to what extent the diverse set of incentives created by the EU ETS actually result in improved energy efficiency.

Acknowledgements The authors would like to thank four anonymous referees for their valuable comments on earlier drafts of this paper. Participants at the European Council for EnergyEfficient Economy Summer Study 2007 in La Colle sur Loup, France, also provided helpful suggestions. Research assistance by Johanna Cludius, Christian Möhrmann, Jakob Rager, Manuel Strauch, and Saskia Ziemann is also acknowledged, as well as proofreading by Gillian Bowman-Koehler and Rob Passey. Parts of this research were sponsored by the Volkswagen Foundation. 


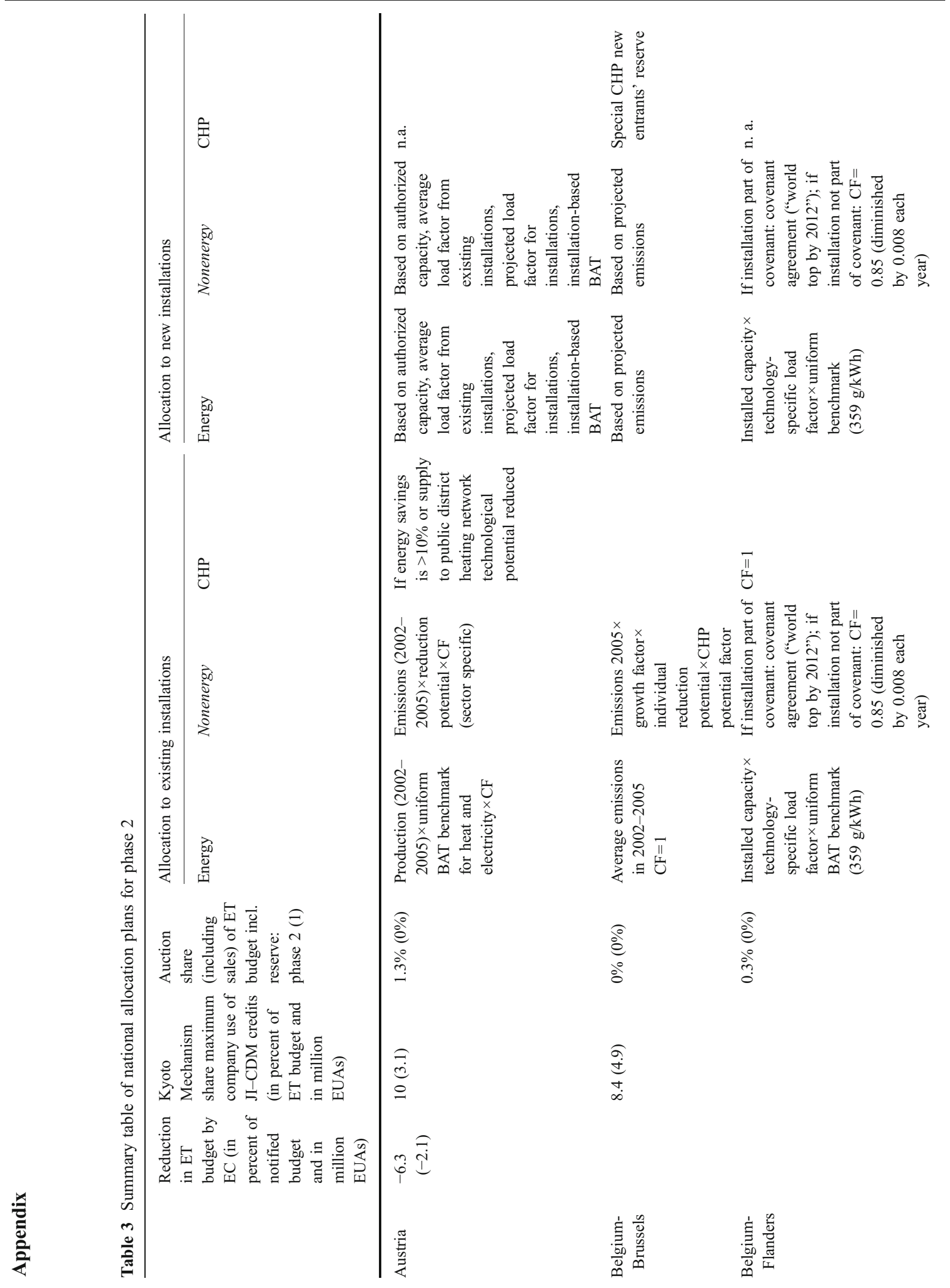


닌

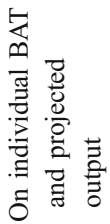

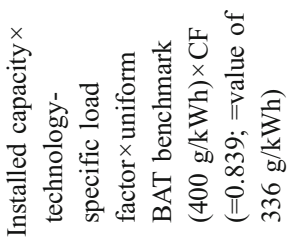

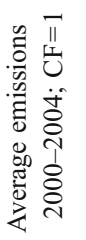

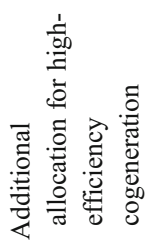

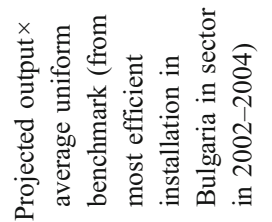

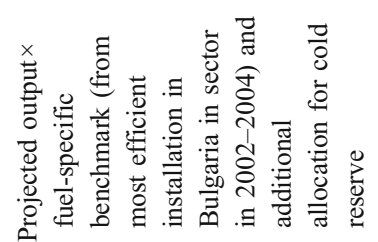

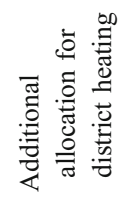

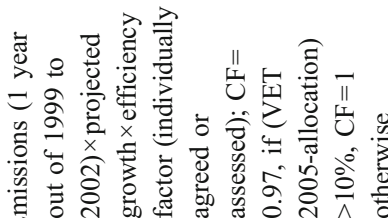
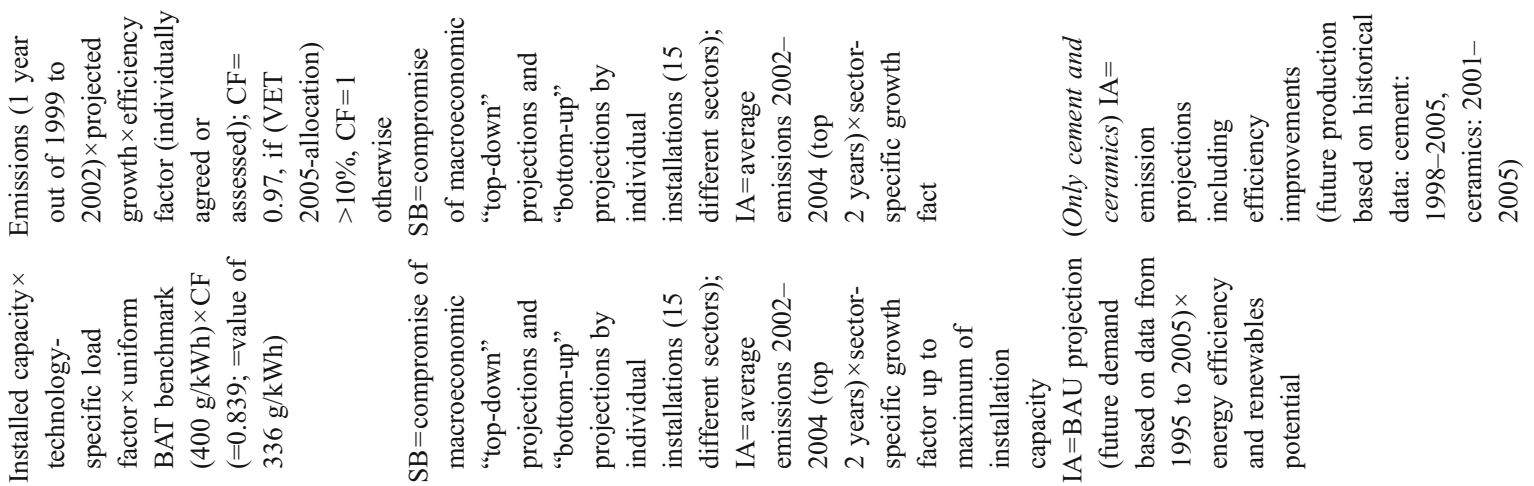

$\frac{8}{8}$

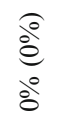

$\frac{8}{8}$

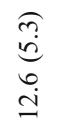

$\stackrel{6}{0}$

站

$\underset{i}{\stackrel{6}{i}}$

窇竞

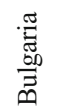

仓ે 


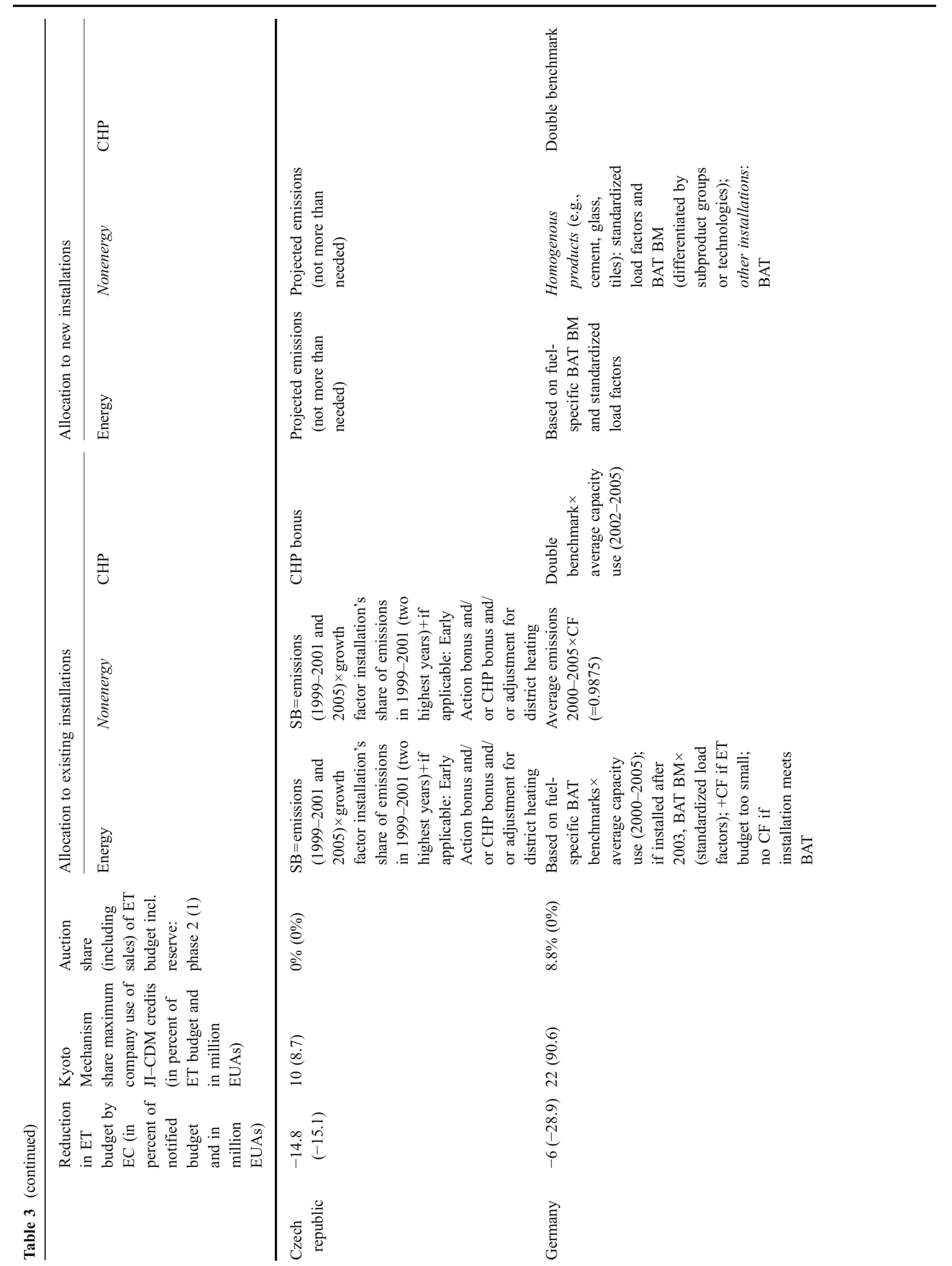




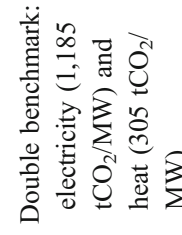

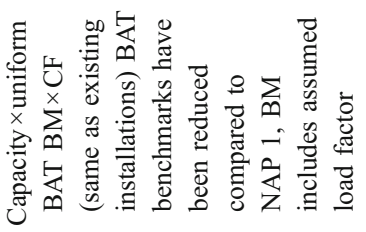

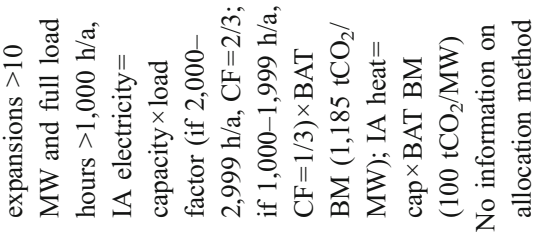

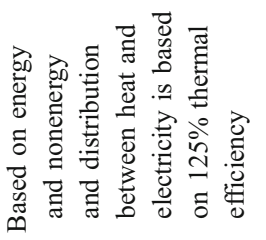

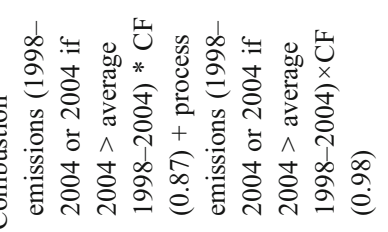

そ

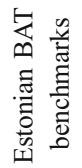

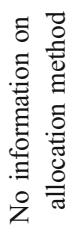

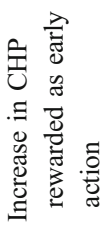

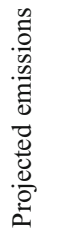

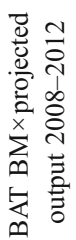

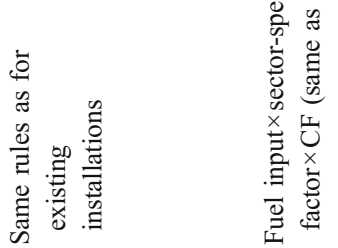

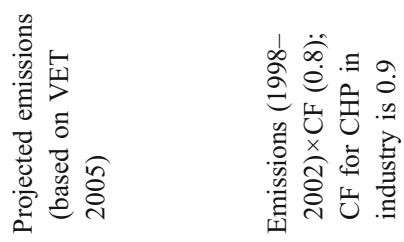

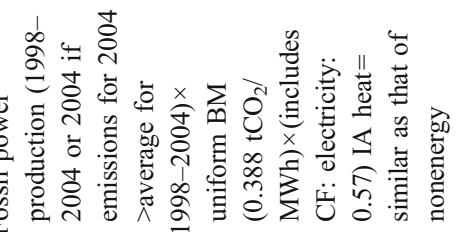

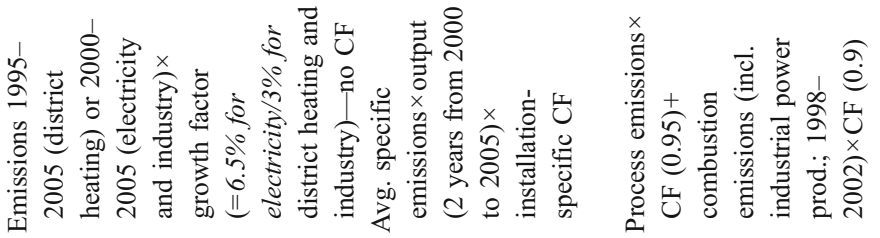

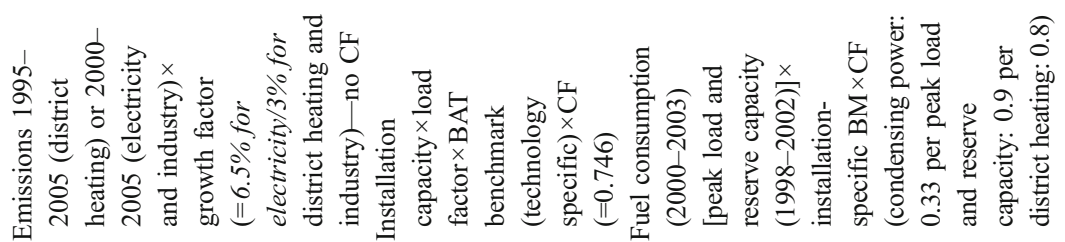

$\frac{\sqrt{\circ}}{\stackrel{\circ}{\circ}}$

$\frac{8}{8}$

$\frac{8}{8}$

$\frac{a}{8}$

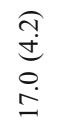

官

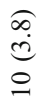

อิ

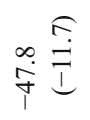

$\hat{i} \stackrel{f}{\stackrel{I}{i}}$

$\vec{i} \stackrel{\widehat{O}}{i}$

疍

ڤี

趌 


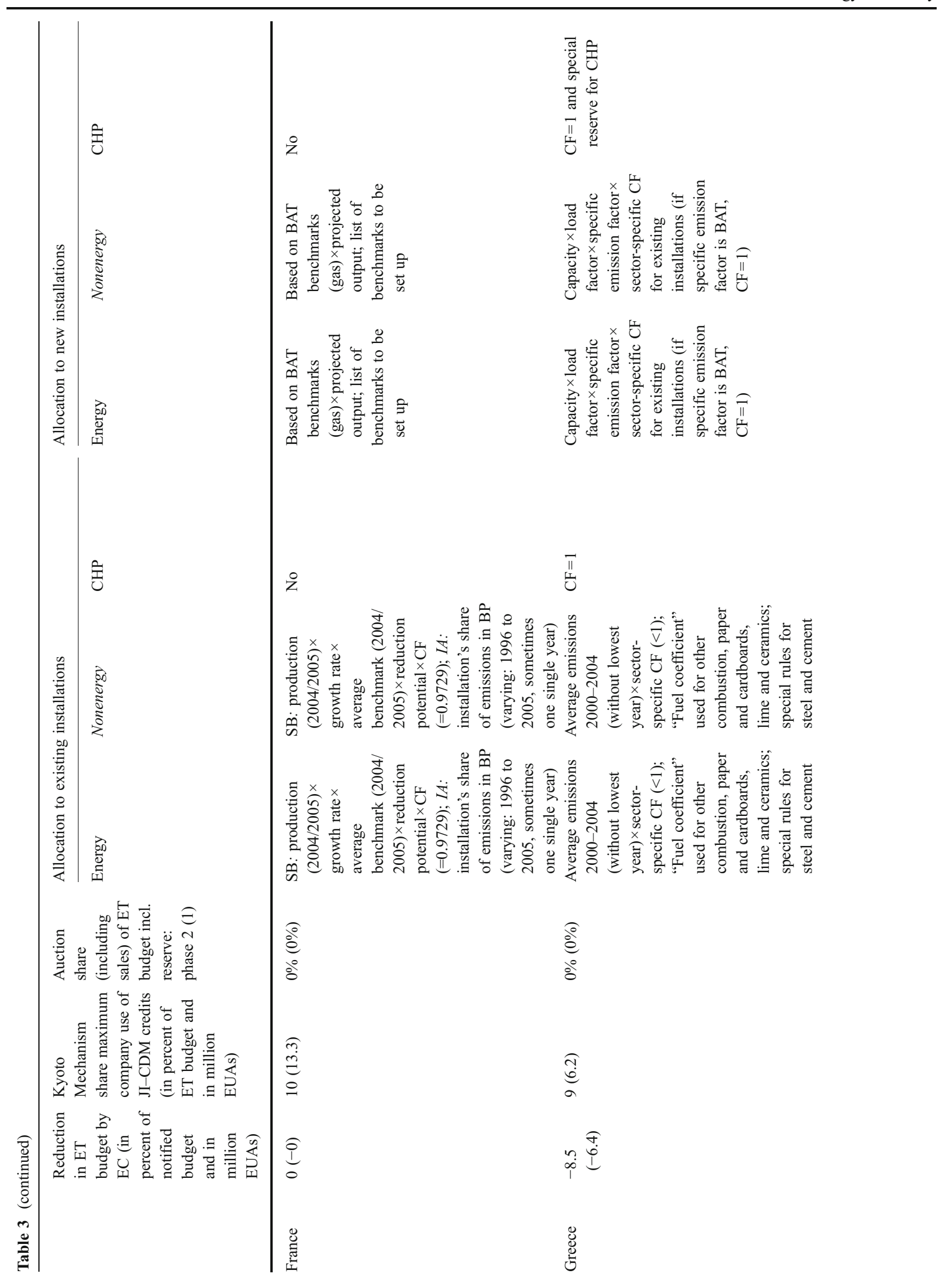




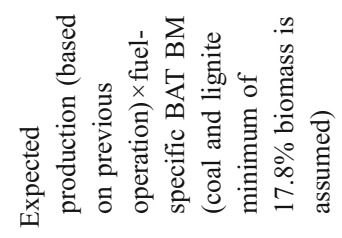

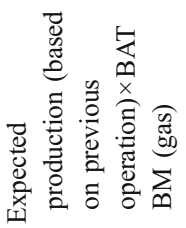

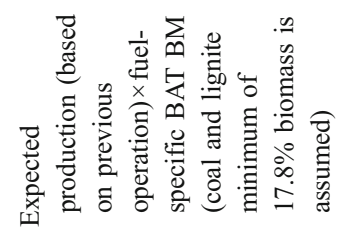

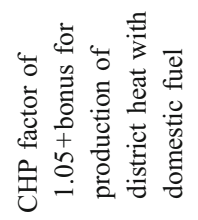

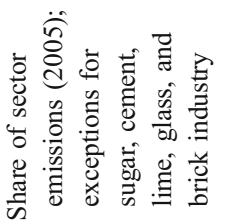

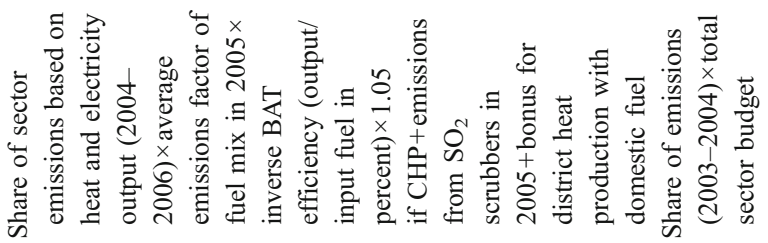

ìं

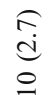

$\underset{i}{\stackrel{\infty}{i}}$

㾍

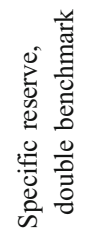

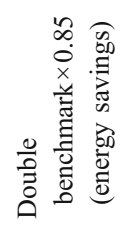

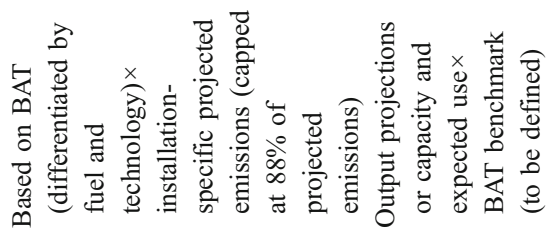

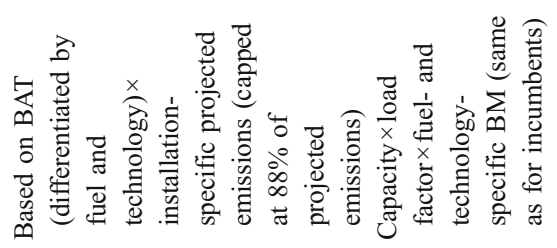

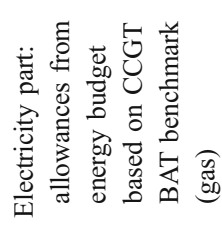

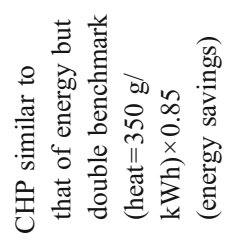

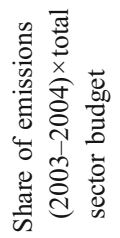

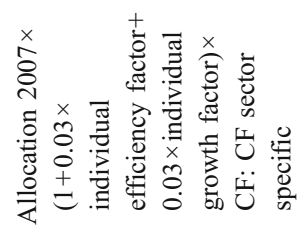

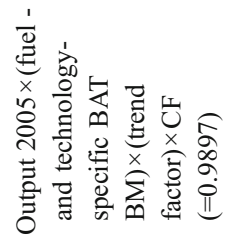

$\frac{8}{8}$

$\underset{\substack{a\\}}{2}$

$+\stackrel{\widehat{a}}{i}$

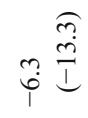

忿 


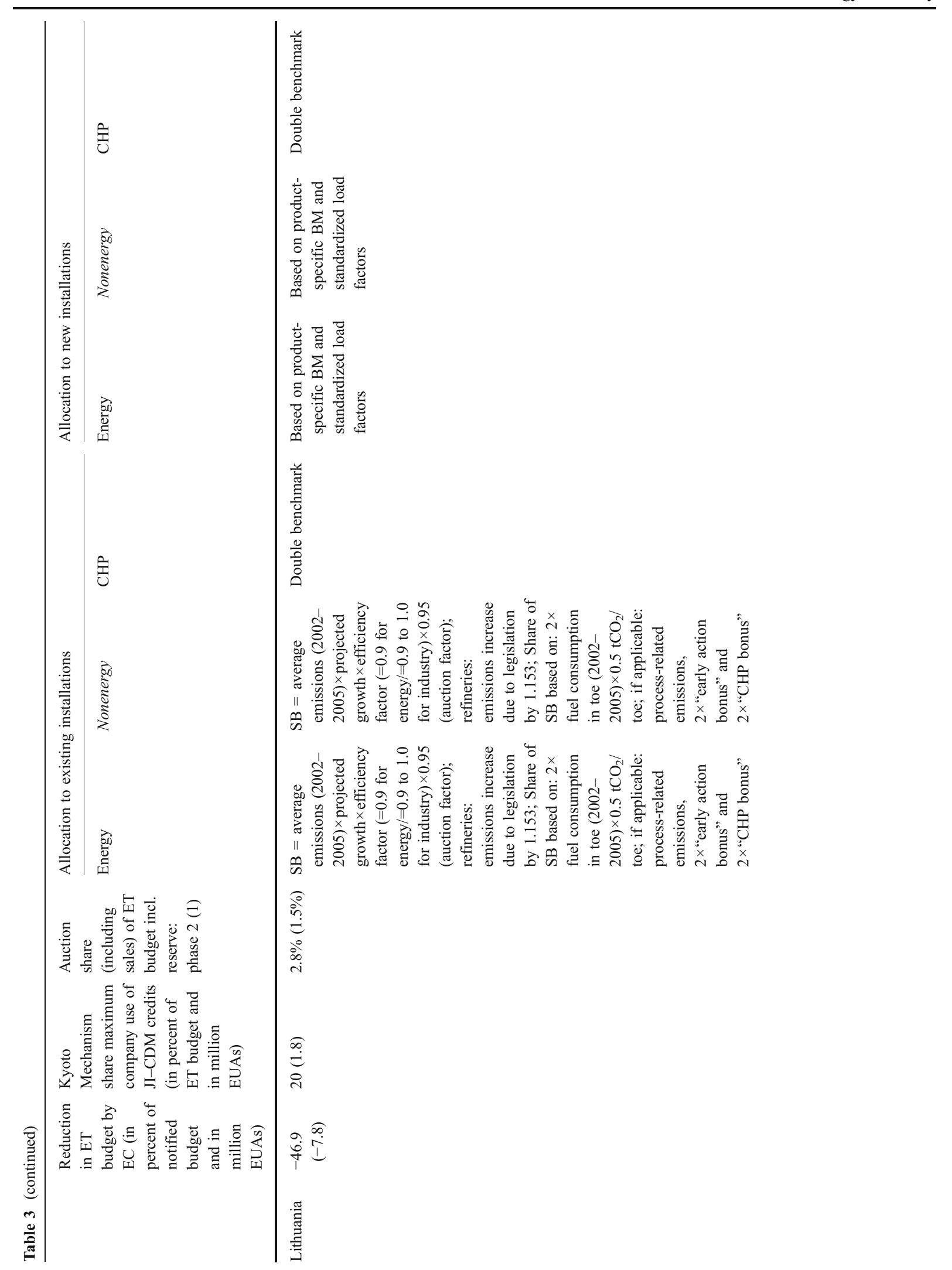



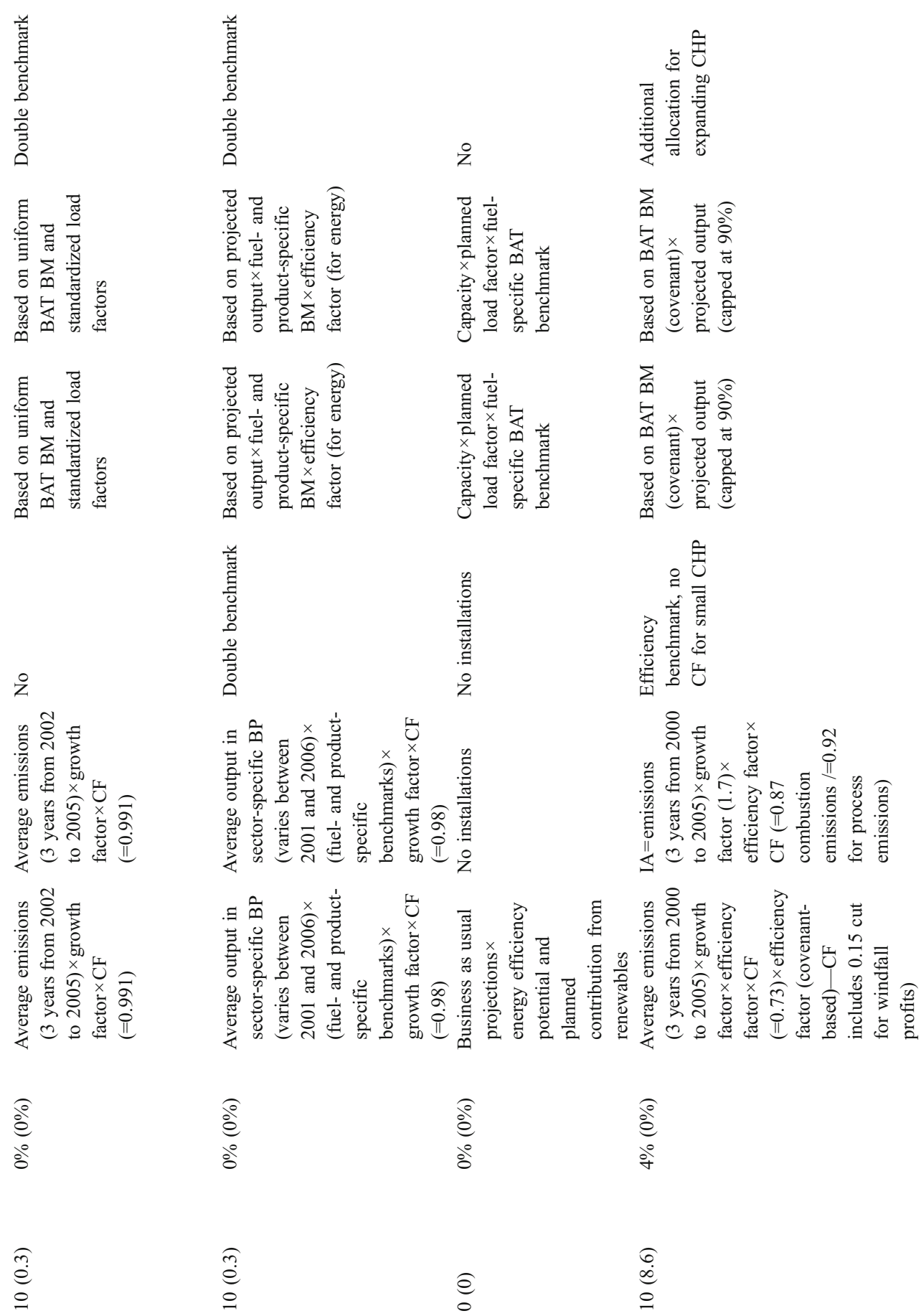

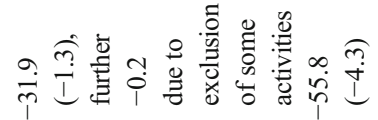

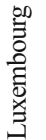

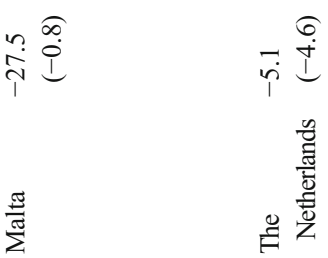




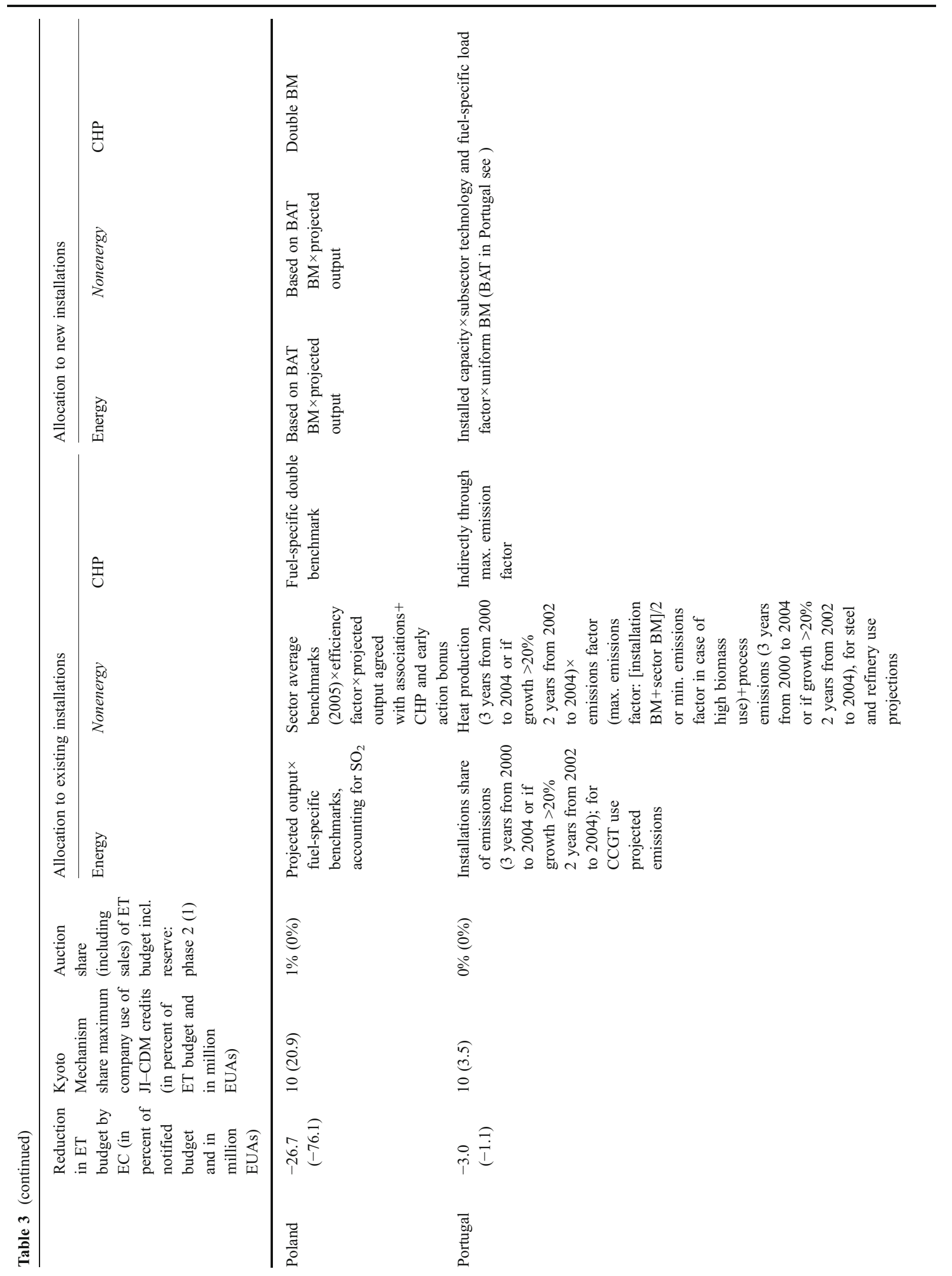




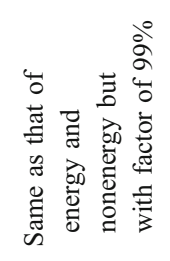

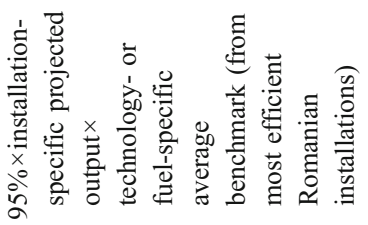

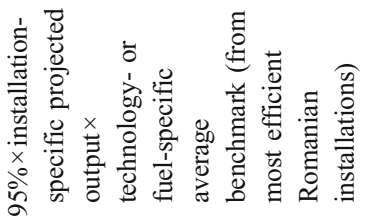

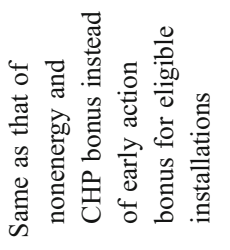

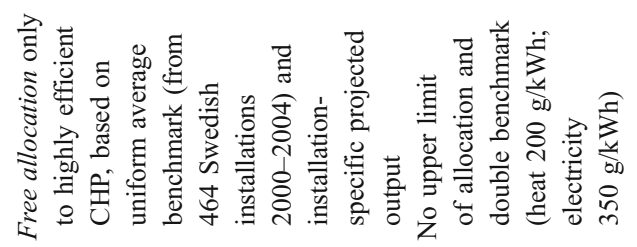

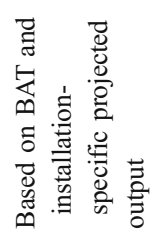

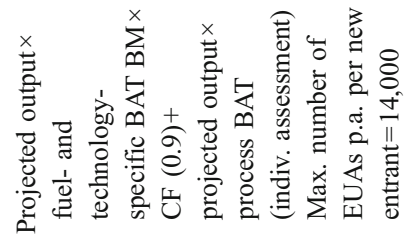

핀

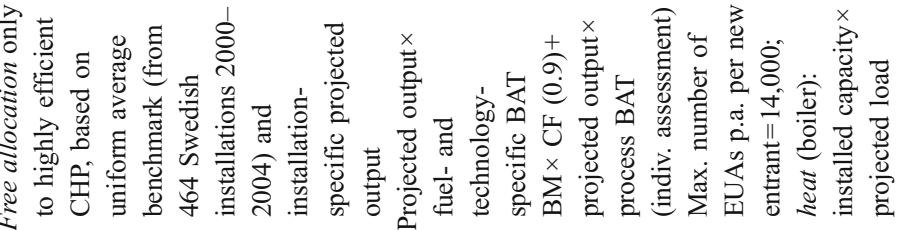

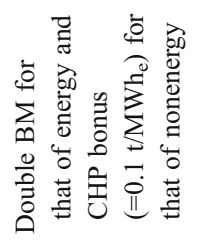

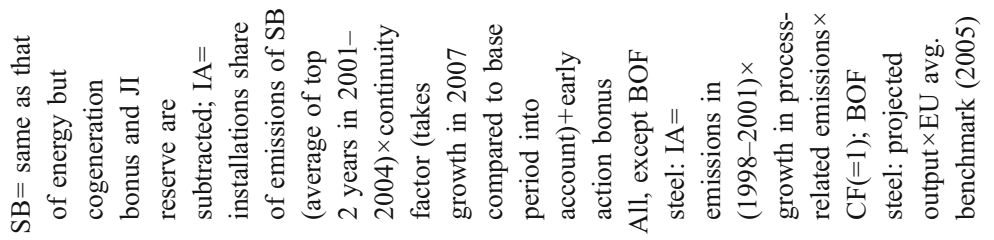

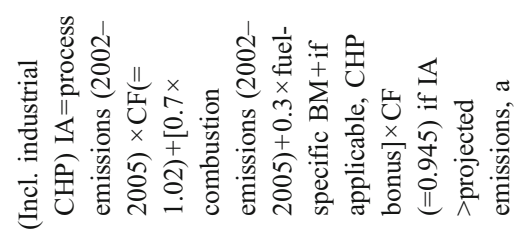

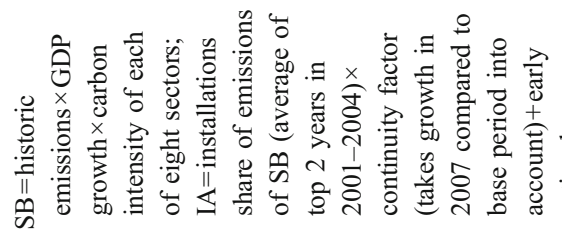

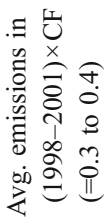

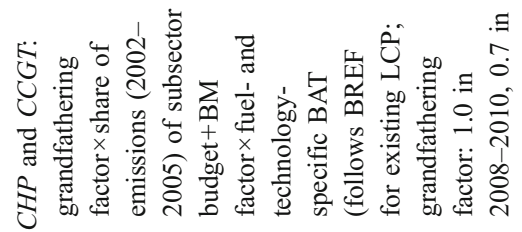

$\frac{\grave{8}}{8}$

$\frac{\widehat{d}}{\dot{0}}$

$\frac{\grave{0}}{\circ}$

$\stackrel{6}{\stackrel{6}{0}}$

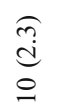

$\underset{\substack{\stackrel{2}{=} \\ \infty}}{\underline{n}}$

๑ัخ

? $\underset{i}{\stackrel{9}{i}}$

oิ

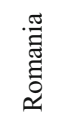

求 


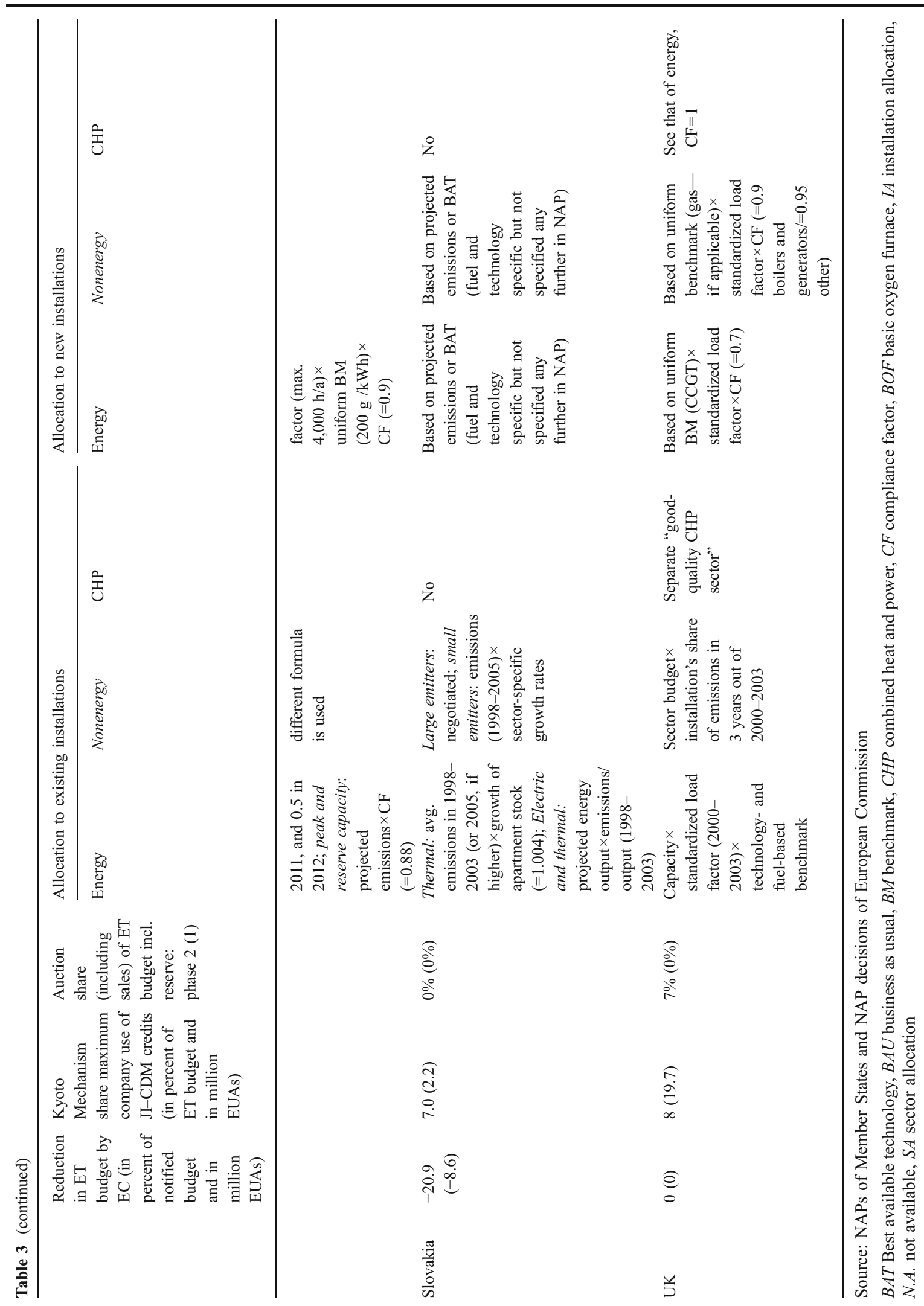




\section{References}

AEA Technology Environment \& Ecofys, (2006). LETS update scoping phase report. http://www.environment-agency.gov. uk/commondata/acrobat/scopingphase_1383666.pdf. Accessed 19 October 19, 2007.

Åhman, M., \& Holmgren, K. (2006). New entrant allocation in the Nordic energy sectors - current principles and options for the EU ETS. Climate Policy, 6, 423-440.

Åhman, M., Burtraw, D., Kruger, J., \& Zetterberg, L. (2007). A tenyear rule to guide the allocation of EU emission allowances. Energy Policy, 35, 1718-1730. doi:10.1016/j.enpol.2006.04.007.

Bertoldi, P., Rezessy, S., \& Bürer, M. J. (2005). Will emission trading promote end-use energy efficiency and renewable energy projects?. Paper presented at the ACEEE Summer study on efficiency in industry of the American Council for Energy Efficient Economy, New York.

Betz, R., Eichhammer, W., \& Schleich, J. (2004). Designing national allocation plans for EU emissions trading - a first analysis of the outcomes. Energy \& Environment, 15, 375-425.

Betz, R., Rogge, K., \& Schleich, J. (2006a). EU emissions trading: An early analysis of national allocation plans for 2008-2012. Climate Policy, 6, 361-394.

Betz, R., Rogge, K., \& Schön, M. (2006b). Domestic climate projects: Limited opportunities in Germany but example for others? Energy \& Environment, 17, 569-582. doi:10.1260/ 095830506778644260.

Böhringer, C., Hoffmann, T., \& Manrique de Lara-Penante, C. (2006). The efficiency costs of separating carbon markets under the EU emissions trading scheme: A quantitative assessment for Germany. Energy Economics, 28, 44-61. doi:10. 1016/j.eneco.2005.09.001.

Bovenberg, A. L., \& Goulder, L. H. (2002). Environmental taxation and regulation. In A. J. Auerbach, \& M. Feldstein (Eds.), Handbook of public economics (vol. 3, (pp. 1474-1545)). Amsterdam: Elsevier.

Bovenberg, A. L., Goulder, L. H., \& Gurney, D. R. (2005). Efficiency costs of meeting industry-distributional constraints under environmental permits and taxes. The Rand Journal of Economics, 36, 951-971.

Brown, M. A. (2001). Market failures and barriers as a basis for clean energy policies. Energy Policy, 29, 1197-1207. doi:10. 1016/S0301-4215(01)00067-2.

Burtraw, D., Palmer, K., \& Kahn, D. (2006). Allocation of $\mathrm{CO}_{2}$ emission allowances in the regional greenhouse gas capand-trade program. The Electricity Journal, 19, 79-90. doi:10.1016/j.tej.2006.01.001.

CEC, (2000). Communication from the Commission to the Council and the European Parliament on EU Policies and Measures to Reduce Greenhouse Gas Emissions: Towards a European Climate Change Programme (ECCP). COM (2000) 88 Final. Brussels, 8 March 2000.

CEC, (2003a). Directive 2003/87/EC of the European Parliament and the Council of 13 October 2003 Establishing a scheme for greenhouse gas emission allowance trading within the community and amending council directive 96/61/EC, OJ L275, 25.10.2003. Brussels, 32-46.

CEC, (2003b). Non-paper on the installation coverage of the EU emissions trading scheme and the interpretation of Annex I. Brussels: CEC.
CEC, (2004a). Directive 2004/101/EC of the European Parliament and the Council of 27 October 2004 amending Directive 2003/87/EC establishing a scheme for greenhouse gas emission allowance trading within the Community, in respect of the Kyoto Protocol's project mechanisms.

CEC, (2004b). Communication from the Commission on guidance to assist Member States in the implementation of the criteria listed in Annex III to Directive 2003/87/EC establishing a scheme for greenhouse gas emission allowance trading within the Community and amending Council Directive 96/ $61 / \mathrm{EC}$, and on the circumstances under which force majeure is demonstrated, Brussels: CEC.

CEC, (2005). Communication from the Commission on further guidance on allocation plans for the 2008 to 2012 Trading Period of the EU Emission Trading Scheme, Brussels: CEC.

CEC, (2006a). Communication from the Commission to the Council and to the European Parliament on the assessment of national allocation plans for the allocation of greenhouse gas emission allowances in the second period of the EU Emissions Trading Scheme accompanying Commission Decisions of 29 November 2006 on the national allocation plans of Germany, Greece, Ireland, Latvia, Lithuania, Luxembourg, Malta, Slovakia, Sweden and the United Kingdom in accordance with Directive 2003/87/EC, Brussels.

CEC, (2006b). Community independent transaction log: National reports on verified emission and surrendered allowances. Brussels: CEC.

CEC, (2006c). EU emissions trading scheme delivers first verified emissions data for installations, IP/06/XXX. Brussels: CEC.

CEC, (2006d). Action plan for energy efficiency: Realising the potential. COM(2006)545 final. Brussels: CEC.

CEC, (2008a). Proposal for a Directive of the European Parliament and of the Council amending Directive 2003/87/ $\mathrm{EC}$ so as to improve and extend the greenhouse gas emission allowance trading system of the Community. COM (2008) xxx, Brussels: CEC.

CEC, (2008b). Communication from the Commission to the European Parliament, the Council, the European Economic and Social Committee and the Committee of the Regions - 20 20 by 2020 Europe's climate change opportunity. COM (2008) 30 final, Brussels: CEC.

CEC, (2008c). Proposal for a decision of the European Parliament and of the Council on the effort of Member States to reduce their greenhouse gas emissions to meet the Community's greenhouse gas emission reduction commitments up to 2020 . COM(2008) 17 final, Brussels: CEC.

Cramton, P., \& Kerr, S. (2002). Tradable carbon permit auctions: How and why to auction not grandfather. Energy Policy, 30, 333-345. doi:10.1016/S0301-4215(01)00100-8.

Cremer, C., \& Schleich, J. (2006). Using benchmarking for the primary allocation of EU allowances in the German power sector. Paper presented at the 29th IAEE International Conference, Potsdam.

Criqui, P., \& Kitous, A. (2003). Kyoto protocol implementation (KPI): Technical report: Impacts of linking JI and CDM credits to the European emissions allowance trading scheme. A report for DG Environment, CNRS-IEPE and ENER DATA S.A. (ed.).

Danish Ministry of the Environment, (2007). Denmark's National Allocation Plan 2008-2012, English courtesy translation of Denmark's National Allocation Plan notified to the European 
Commission 7 March 2007. http://www.mst.dk/NR/rdon lyres/3123145C-A515-4DB7-B877-6C74410F9E5C/ 38145/20070312danishallocationplanenglishcourtesy transla.pdf. Accessed 19 October 2007.

EEA (2006). Greenhouse gas emission trends and projections in Europe, EEA report. Copenhagen: EEA.

Ehrhart, K.-M., Hoppe, C., Schleich, J., \& Seifert, S. (2005). The role of auctions and forward markets in the EU ETS: Counterbalancing the cost-inefficiencies of combining generous allocation with a ban on banking. Climate Policy, 5, 31-46.

Ehrhart, K.-M., Hoppe, C., \& Löschel, R. (2008). Abuse of EU emissions trading for tacit collusion. Environmental and Resource Economics, in press.

Ellerman, A. D. (2008). New entrant and closure provisions: How do they distort? The Energy Journal, 29(Special Issue in honor of Campbell Watkins), 63-76.

Ellerman, A. D., \& Buchner, B. (2007). The European union emissions trading scheme: Origins, allocation, and early results. Review of Environmental Economics and Policy, 1, 66-87. doi:10.1093/reep/rem003.

Ellerman, A. D., \& Buchner, B. (2008). Over-allocation or abatement? A preliminary analysis of the EU ETS based on the 2005-06 emissions data. Resource and Environmental Economics, in press.

Ellerman, A. D., Joskow, P. L., \& Harrison, D. (2003). Emissions trading in the US: Experience, lessons and considerations for greenhouse gases. Arlington, VA, Pew Center on Global Climate Change.

Fischer, C. (2005). Technical innovation and design choices for emissions trading and other climate policies. In B. Hansjürgens (Ed.), Emissions trading for climate policy: US and European perspectives (pp. 37-52). Cambridge: Cambridge University Press.

Fischer, C., Parry, I., \& Pizer, W. A. (2003). Instrument choice for environmental protection when annex: Summary table of national allocation plans for phase 2 technological innovation is endogenous. Journal of Environmental Economics and Management, 45, 523-545. doi:10.1016/S0095-0696(03) 00002-0.

Gagelmann, F., \& Frondel, M. (2005). E. T. and innovationScience fiction or reality? An assessment of the impact of emissions trading on innovation. European Environment, 15, 203-211. doi:10.1002/eet.387.

Grubb, M., \& Ferrario, F. (2006). False confidences: Forecasting errors and emission caps in $\mathrm{CO}_{2}$ trading systems. Climate Policy, 6, 495-501.

Hepburn, C., Grubb, M., Neuhoff, K., Matthes, F., \& Tse, M. (2006). Auctioning of the EU ETS phase II allowances: how and why? Climate Policy, 6, 137-160.

Honkatukia, J., Mälkönen, V., \& Perrels, A. (2006). The impact of the European Emission trade system on Finnish wholesale electricity prices. VATT Discussion Paper 405. VATT Government institute for economic research, Helsinki. http://en.vatt.fi/file/vatt_publication_pdf/k405.pdf. Accessed 1 October 2007.

Hourcade, J. C., Demailly, D., Neuhoff, K., \& Sato, M. (2008). Differentiation and dynamics of EU ETS industrial competitiveness impacts climate strategies report. Climate Strategies, London. http://www.climate-strategies.org/uploads/ ClimateStrategies_competitiveness_final_report_140108. pdf. Accessed 28 January 2008.
IPCC, (2005). Carbon dioxide capture and storage. Intergovernmental Panel on Climate Change Special Report on Carbon Dioxide Capture and Storage. http://arch.rivm.nl/ env/int/ipcc/pages_media/SRCCS-final/IPCCSpecial ReportonCarbondioxideCaptureandStorage.htm. Accessed 26 January 2008.

Ismer, R., \& Neuhoff, K. (2006). Commitments through financial options: A way to facilitate compliance with climate change obligations, Working Paper EPRG0625. http://www.electricitypolicy.org.uk/pubs/wp/eprg0625.pdf. Accessed 1 October 2007.

Jaffe, A. B., \& Stavins, R. N. (1994a). Energy-efficiency investments and public policy. The Energy Journal, 15, 43-65.

Jaffe, A. B., \& Stavins, R. N. (1994b). The energy-efficiency gap: What does it mean? Energy Policy, 22, 804-810. doi:10. 1016/0301-4215(94)90138-4.

Keats Martinez, K., \& Neuhoff, K. (2005). Allocation of carbon emission certificates in the power sector: How generators profit from grandfathered rights. Climate Policy, 5, 61-78.

Kettner, C., Köppl, A., Schleicher, S. \& Thenius, G. (2007). Stringency and distribution in the EU emissions trading scheme-The 2005 evidence. Nota di Lavora 22.2007 Fondazione Eni Enrico Mattei.

Matthes, F., Graichen, V., \& Repenning, J. (2005). The environmental effectiveness and economic efficiency of the European Union emissions trading scheme: Structural aspects of allocation. Berlin: Öko-Institut.

McKinsey \& Ecofys (2006). Review of EU emissions trading scheme-Survey results. Brussels: European Commission, DG Environment.

Milliman, S. R., \& Prince, R. (1989). Firm incentives to promote technological change in pollution control. Journal of Environmental Economics and Management, 17, 247-265. doi:10.1016/0095-0696(89)90019-3.

Montgomery, D. (2005). Creating technologies to reduce greenhouse gas intensity: Public options and opportunities. Washington, DC: George C. Marshall Institute.

National Emissions Trading Taskforce, (2006). Discussion paper: Possible design for a national emissions trading scheme. Discussion paper. http://www.emissionstrading. nsw.gov.au/_data/assets/pdf_file/0010/2017/Discussion_ Paper_-_Full_document.pdf.

Neuhoff, K., Keats Martinez, K., \& Sato, M. (2006). Allocation, incentives and distortions: the impact of EU ETS emissions allowance allocations to the electricity sector. Climate Policy, 6, 73-91.

Ostertag, K. (2003). No-regret potentials in energy conservation: An analysis of their relevance, size and determinants. Physica: Heidelberg.

Peterson, S. (2006). Efficient abatement in separated carbon markets: A theoretical and quantitative analysis of the EU Emissions Trading Scheme, Working Paper No. 1271, Kiel.

Peterson, E., \& Schleich, J. (2007). Economic and environmental effects of border-tax adjustments. Fraunhofer ISI Working Paper Sustainability and Innovation No. S1/2007 (revised version October 2007).

Phaneuf, D. J., \& Requate, T. (2002). Incentives for investment in advanced pollution abatement technology in emission permit markets with banking. Environmental and Resource Economics, 22, 369-390. doi:10.1023/A:1016097000190. 
Prime Ministerial Task Group on Emissions Trading, (2007). Report of the Task Group on emissions trading. Prime Minister, Canberra. http://www.pmc.gov.au/publications/ emissions/index.cfm. Accessed 1 October 2007.

Ramsey, F. P. (1927). A contribution to the theory of taxation. The Economic Journal, 37, 47-61. doi:10.2307/2222721.

Reinaud, J. (2007). $\mathrm{CO}_{2}$ Allowance \& Electricity Price Interaction-Impact on industry's electricity purchasing strategies in Europe. IEA Information Paper, OECD/IEA, Paris.

Requate, T. (2005). Dynamic incentives by environmental policy instruments-A survey. Ecological Economics, 54, 175-195. doi:10.1016/j.ecolecon.2004.12.028.

Rogge, K., Schleich, J., \& Betz, R. (2006). An early assessment of national allocation plans for phase 2 of EU emission trading, 01/06, Fraunhofer ISI Working Papers Sustainability and Innovation, Karlsruhe: Fraunhofer ISI. http:// www.isi.fhg.de/n/Projekte/pdf/NAP2_assessment.pdf. Accessed 1 August 2007.

Røine, K., \& Hasselknippe, H. (2007). Carbon 2007-A new climate for carbon trading. Oslo: Point Carbon.

Schleich, J., \& Betz, R. (2005). Incentives for energy efficiency and innovation in the European emission trading system. Paper presented at the ECEEE Summer Study, Mandelieu, France.

Schleich, J., Ehrhart, K.-M., Hoppe, C., \& Seifert, S. (2006). Banning banking in EU-emissions trading? Energy Policy, 34, 112-120. doi:10.1016/j.enpol.2004.06.009.
Schmalensee, R., Joskow, P., Ellerman, D., Montero, P., \& Baily, E. (1998). An interim evaluation of sulfur dioxide emissions trading. The Journal of Economic Perspectives, 12, 53-68.

Sijm, J., Bakker, S., Chen, Y., Harmsen, H. \& Lise, W. (2005). $\mathrm{CO}_{2}$ price dynamics. The implications of EU emissions trading for the price of electricity, ECN-C-05-081, Petten.

Sijm, J. P., Neuhoff, K., \& Chen, Y. (2006). CO2 cost passthrough and windfall profits in the power sector. Climate Policy, 6, 49-72.

Sorrell, S., O'Malley, E., Schleich, J., \& Scott, S. (2004). The economics of energy efficiency-Barriers to cost-effective investment. Edward Elgar: Cheltenham.

Spulber, D. F. (1985). Effluent regulation and long-run optimality. Journal of Environmental Economics and Management, 12, 103-116. doi:10.1016/0095-0696(85)90021-X.

Sterner, T., \& Muller, A. (2006). Output and abatement effects of allocation readjustment in permit trade. Resources for the future discussion paper 06-49, Washington, DC: Resources for the Future.

UNFCCC. (2006). National inventory submissions. Bonn: UNFCCC.

World Bank (2008). State and trends of the carbon market 2008. Washington D.C: World Bank.

Zetterberg, L., Nilsson, K., Åhman, M., Kumlin, A.-S., \& Birgersdotter, L. (2004). Analysis of national allocation plans for the EU ETS. IVL-report B 1591, Stockholm, Sweden. 